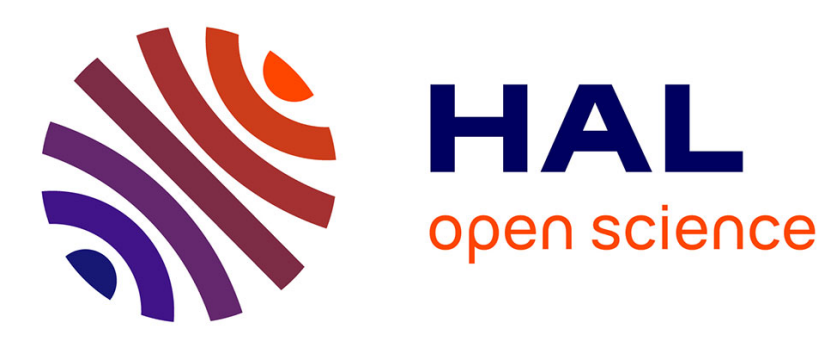

\title{
Parafoveal-on-foveal interactions in word recognition
} Alan Kennedy, Joël Pynte, Stéphanie Ducrot

\section{To cite this version:}

Alan Kennedy, Joël Pynte, Stéphanie Ducrot. Parafoveal-on-foveal interactions in word recognition. Quarterly Journal of Experimental Psychology, 2002, 55 (4), pp.1307 - 1337. 10.1080/02724980244000071 . hal-03536308

\section{HAL Id: hal-03536308 \\ https://hal.science/hal-03536308}

Submitted on 19 Jan 2022

HAL is a multi-disciplinary open access archive for the deposit and dissemination of scientific research documents, whether they are published or not. The documents may come from teaching and research institutions in France or abroad, or from public or private research centers.
L'archive ouverte pluridisciplinaire $\mathbf{H A L}$, est destinée au dépôt et à la diffusion de documents scientifiques de niveau recherche, publiés ou non, émanant des établissements d'enseignement et de recherche français ou étrangers, des laboratoires publics ou privés. 


\title{
Parafoveal-on-Foveal interactions in Word Recognition ${ }^{\mathrm{i}}$
}

\author{
Alan Kennedy, \\ University of Dundee, Dundee, Scotland \\ Joël Pynte and Stéphanie Ducrot \\ CNRS and Université de Provence
}

Address for correspondence:

Professor Alan Kennedy Psychology Department, The University, Dundee, DD1 4HN, Tayside, Scotland

Fax:+(44) (1382) 229993

email: a.kennedy@dundee.ac.uk 
There is a growing amount of evidence suggesting that properties of an unfixated word in parafoveal vision may influence current processing time. Unfortunately, there are also a number of inconsistencies in the literature regarding both the size and direction of the obtained effects. Low constraint in a parafoveal word's initial letters appears to increase or decrease foveal processing time, depending on parafoveal word frequency and, similarly, lowfrequency parafoveal word may increase or decrease foveal processing time, depending of such factors as the experimental task, the length of the relevant words and the distribution of information within them. Earlier studies did not systematically manipulate the relevant stimulus properties. In this paper, we manipulate the length and frequency of a given foveal word, together with the length, frequency and initial letter constraint of an associated parafoveal word. Gaze and refixation rate on the foveal word were measured as a function of properties of the parafoveal target word. The results confirm the existence of parafoveal-onfoveal effects and suggest that the apparent inconsistencies in the literature relate to a failure to control for foveal word length. The pattern of obtained effects cannot be accounted for by a serial-sequential attention switching model of eye movement control. The data are also incompatible with various forms of parallel processing model. They are vest accounted for by postulating a process-monitoring mechanism, sensitive to the simultaneous rate of acquisition of information from foveal and parafoveal sources. 
This paper is concerned with the relationship between attention and eye movement control in reading. Its starting point is the highly influential proposal, initially put forward by Morrison (1984), that the reader's attention shifts in a serial fashion, as lexical access is secured to each successive fixated word (see Henderson, 1992, for a review). That is, once processing of a word in the fovea is complete, the reader can begin work on the next word before actually looking at it. Such covert shifts of attention account for the well-documented parafoveal preview advantage (Rayner, 1998, Rayner \& Pollatsek, 1989). Morrison proposed that covert attentional shifts and overt inter-word saccades were triggered by the same cognitive event (word identification) leading to the prediction that preview advantage should be independent of foveal load and relatively constant, because pre-processing of a word can only take place during the time needed to prepare and execute a saccade towards it. It subsequently proved difficult to reconcile this claim with data showing that the preview advantage actually varies as a function of foveal load (Henderson \& Ferreira, 1990).

Broadly speaking, two possible responses can be made to evidence of foveal-onparafoveal interactions. The first response is to modify the Morrison model, while preserving its essential characteristic of an attentional switch, operating serially from word to word. This was the approach adopted by Henderson and Ferreira who suggested that inspection time would not be extended indefinitely on a given word: eventually a saccade becomes inevitable, whether or not lexical access has been achieved (Henderson \& Ferreira, 1990). The operation of such a 'saccadic deadline' predicts a reduction in preview advantage with increasing foveal inspection time, but unfortunately also predicts an increase in intra-word refixations, for which there is no evidence (Schroyens, Vitu, Brysbaert \& d'Ydewalle, 1999) and neglects the commonplace observation that very long fixations frequently occur, even for skilled readers (see, for example, Rayner, 1995, Figure 2). Furthermore, when two fixations are made on a 
word, the first is quite often shorter (Kleigl, Olson \& Davidson, 1982), which is incompatible with the operation of a processing deadline ${ }^{\mathrm{ii}}$. Henderson and Ferreira did not, in fact, test an obvious prediction from the deadline proposal, that foveal-on-parafoveal effects should be restricted to cases where only a single long fixation is made on a foveal word, but this has recently been shown not to be the case (Schroyens et al, 1999).

A more comprehensive modification to the Morrison model, the E-Z Reader model, was proposed by Reichle, Pollatsek, Fisher and Rayner (1998). In this computationally explicit revision a shift in covert attention remains contingent on lexical access, but the cognitive event triggering an eye movement is taken to be completion of a pre-lexical familiarity check on the fixated word. Covert attention will normally precede overt gaze, because saccades take time to plan and execute, but this will not invariably be the case. The E-Z Reader model predicts word-skipping, short-duration fixations, and 'spillover' effects such as those reported by Rayner and Duffy (1986); and provides a good statistical fit to observations of refixation rate and fixation duration as a function of word frequency. It also elegantly accounts for the interaction of preview advantage with foveal load without sacrificing the commitment to the serial allocation of attention. However, although control over covert attentional shifts and overt eye movements is decoupled in the E-Z Reader model, it retains the central assumption that attention is allocated from word to word in a strictly serial sequential fashion ${ }^{\mathrm{iii}}$.

The second response to the observation that preview advantage changes as a function of foveal load is to suggest that foveal and parafoveal words are, do some degree, processed in parallel. In fact, in proposing saccade preparation in the absence of an attentional shift the $E$ Z Reader model allows for a limited amount of parallel processing. But while foveal-onparafoveal interactions might be accommodated in this way, effects in the reverse direction (parafoveal-on-foveal) cannot. In a serial-sequential model, properties of a word in the 
parafovea cannot influence current foveal processing because information from an extrafoveal source only becomes available after attention has been switched away from the fovea. Several recent demonstrations of just such parafoveal-on-foveal cross-talk consequently represent a serious challenge to the notion that attention is allocated in a serial fashion word by word. For example, Schroyens et al (1999) measured eye movements as participants scanned a sequence of three words looking for (rare) instances of items of clothing. One critical condition involved systematic manipulation of both foveal and parafoveal word frequency. Consistent with the data of Henderson and Ferreira (1990; 1993), preview advantage was greater for high frequency foveal stimuli than for low frequency. However, contrary to predictions from the serial allocation model, this difference itself was modulated by parafoveal word frequency. Kennedy (2000a), using the same 'clothing search' task, also showed an influence on foveal inspection time exerted from properties of an unfixated word in the parafovea: foveal gaze was shorter when a parafoveal target was a high frequency word, but this was only the case if its initial letters were redundant. For parafoveal targets with highly constrained initial letters, foveal inspection time was actually longer for high frequency items. A second experiment asked participants to execute a sequence of saccades before reading the same experimental items, with the aim of making the task more like normal reading. Under these circumstances, lexical properties of parafoveal words had little effect on foveal processing but there was a continuing effect exerted by the initial letter constraint of the parafoveal target, with longer foveal gaze associated with redundant initial letters (i.e. the initial letters of the parafoveal word were relatively 'uninformative', using the definition adopted by Pynte, Kennedy and Murray, 1991). 
A number of subsequent experiments have confirmed the existence of parafoveal-onfoveal effects at both sub-lexical and lexical levels, albeit with inconsistencies in the direction of obtained differences. With regard to sub-lexical sources of influence, Underwood, Binns and Walker (2000) examined eye movements during the reading of short narratives containing sentences like "he found the rake awkward to handle" versus "he found the rake compact to handle". For a defined foveal word (e.g. rake) the experiment manipulated the constraint of the initial letters of a seven-letter low frequency parafoveal target word, (e.g. awkward or compact). Contrary to the results for the equivalent low frequency condition in Kennedy (2000a), foveal gaze was significantly shorter when the parafoveal word had a redundant initial trigram. A similar inconsistency exists regarding the direction of lexical parafoveal effects. As noted above, Kennedy (2000a) showed that when a parafoveal target shared its first three letters with very few other words a form of 'reversed frequency effect' was obtained, with a significant increase in foveal gaze (i.e. more within word refixations) when a high frequency word was in the parafovea. This was not found in the analysis of a corpus of data derived from normal text processing (Kennedy, 1998), possibly because of a failure to control for initial letter constraint of target words. It is also inconsistent with the results of Experiment 1 reported by Inhoff, Radach, Starr and Greenberg (2000). This compared eye movements on the word "mother's" in sentences like "did you see the picture of her mother's mother at the wedding?" versus "did you see the picture of her mother's garden at the wedding?". It seems plausible that the low foveal load resulting from repetition is similar to that resulting from the processing demands of a high frequency word, but Inhoff et al showed that foveal gaze was reliably shorter (not longer) when the parafoveal stimulus involved a repeated word. Finally, Murray (1998) provided compelling evidence of parafoveal-on-foveal effects, in an 'orthodox' direction, operating at a pragmatic level. He used a sentence 
comparison task, involving a decision as to whether two instances of sentences such as 1a or $1 \mathrm{~b}$ were identical. The principal manipulation was the plausibility of the relationship between the first noun and the verb; and the verb and the second noun. Word frequency of the relevant items was carefully controlled. Comparison of reading times for sentence-pairs $1 \mathrm{a}$ and $1 \mathrm{~b}$ showed a marked plausibility effect, with fixation time on the verb stacked shorter when associated with the more plausible first noun (hunters rather than bishops). However, Murray also found that fixation time on the first noun phrase itself was shorter when a verb not yet fixated (e.g. stacked) provided a more plausible continuation of the sentence. That is, foveal fixation time appears to be modulated by parafoveal pragmatic information.

(1a) The bishops stacked the tulips The bishops stacked the tulips

(1b) The hunters stacked the tulips The hunters stacked the tulips

Evidence of parafoveal-on-foveal processing interactions suggests that the assumption of a strictly serial-sequential allocation of attention may have to be considerably revised or abandoned. Attention appears either to be allocated to discrete locations simultaneously (Hoffman, 1998) or distributed as a gradient across a region involving more than one word (Inhoff, et al; Schroyens et al, 1999; Schiepers, 1980). In parallel processing accounts of this kind parafoveal-on-foveal effects might be reflected in the timing of eye movement control (the 'when?' decision) and/or the location of successive fixations (the 'where?' decision). There is a large body of evidence suggesting that these two decision are under relatively independent sources of control, with low-level factors, such as word length, influencing saccade targeting and higher-level linguistic factors affecting fixation duration (see Findlay \& Walker, 1999, for a review). Considering the when decision first, a gradient of attention 
might be adjusted to allow for the processing of an increasing number of neighbouring letters and words ${ }^{\text {iv }}$. 'Foveal' inspection time then becomes, in effect, an index of global processing efficiency and will vary as a function of parafoveal difficulty, reflecting such properties as initial letter constraint, lexical status, or even the plausibility, of words yet to be fixated. Two versions of such a parallel model are possible, generating opposing predictions. In the first (pure parallel processing), each fixation initiates processing of a string of letters, which may comprise more than one word, limited only by considerations of acuity. Broadly speaking, the longer a given foveal word is fixated, the more parafoveal processing can occur. In the second version, attention is considered as a limited resource (distributed parallel processing), and parafoveal processing becomes dependent on foveal success. From this perspective, extended fixation on a given foveal word reflects an increased demand on attentional resources, with the result that less, rather than more, parafoveal processing will occur.

It is tempting to dismiss parallel processing models (of either form) on the grounds that they represent an attempt to reintroduce the discredited notion of 'visual span control' into theories of reading (see Deubel, O'Regan \& Radach, 2000, for a discussion). That is, some early studies of reading suggested that visual acuity might be the primary constraint on processing, reducing eye movement control to a sequence of fixations, each shifting the eyes to a point beyond the right limit of the array of letters currently visible. Within that array it could be assumed that information was processed in parallel. But there is no evidence that visual span acts to modulate saccade extent in this way. Indeed, the reverse is clearly the case: average saccade extent compensates almost perfectly for viewing distance ${ }^{\mathrm{v}}$ (Morrison \& Rayner, 1981; O’Regan, 1989; 1990): it is not possible to process more words by moving further away from the text. However, there is abundant evidence, deriving from use of contingent display techniques (McConkie \& Rayner, 1975; Rayner, 1975) that perceptual span 
in a task as complex as reading must be distinguished from visual acuity. For readers of English, lexical and sublexical information is available across an asymmetric region extending up to 15 characters to the right and much less to the left. The 'availability' of this parafoveal information underpins the preview benefit. The issue addressed in this paper, therefore, is not whether parafoveal information is available, but when and, in particular, the visual attention is deployed across the span.

The processing difficulty hypothesis proposed by Hyönä and co-workers (Hyönä,1995; Hyönä \& Pollatsek, 2000) focuses on the where of eye movement control, rather than the when. The perceptual span is defined as an area around the fixation point which shrinks or expands as a function of global processing difficulty, which may involve both foveal and parafoveal properties. Although drawing on the notion of a flexible attentional span, it is important to note that Hyönä and co-workers argue that this is compatible with the operation a sequential attentional device. The hypothesis consequently posits a kind of hybrid mechanism, accepting that attentional span might change with processing load, but rejecting the notion of parallel processing across the span. Thus, while the processing difficulty hypothesis does not predict parafoveal effects on concurrent foveal gaze duration, it does predict a parafoveal influence over saccade targeting, changes in the 'focus' of the attentional spotlight acting to modulate the landing position of primary inter-word saccades. Under the assumptions of pure parallel processing (which Hyönä et al reject) such a hypothesis would predict that a long foveal fixation duration should be followed by a landing position further to the right on the chosen target because more processing in the right visual field will have taken place (Pollatsek, Rayner \& Balota, 1986). Under the assumptions of serial-sequential attention switching (or, in fact, distributed parallel processing), the hypothesis predicts that 
landing position should be left-shifted ${ }^{\mathrm{vi}}$ and there is evidence to support this position (Hyönä, 1995; Hyönä \& Pollatsek, 1998).

In fact, a sharp distinction between when and where decisions may be difficult to sustain. As Kennedy (1998) points out, the two decisions interact, because shifts in position inevitably lead to changes in the visibility of potential targets, with consequential changes in processing load. An obvious illustration of this is the tension between the decision to continue a fixation and the decision to launch a saccade (STAY versus GO) discussed by Henderson and Ferreira (1990). As noted above, the proposal that the expiry of a deadline might lead to the launch of 'premature' saccades, executed before foveal processing has been completed, fails for lack of experimental support: there is little or no evidence that 'late' saccades of this kind occur. On the other hand, unusual and/or difficult stimulus configurations in the parafovea do appear to trigger 'early' premature saccades. This observation led Kennedy (1998) to propose an alternative distributed parallel processing account, involving a process-monitoring mechanism, sensitive to the rate of acquisition of foveal and parafoveal information (henceforth process monitoring). In this account, parafoveal-on-foveal effects are mediated primarily by changes in refixation rate (i.e. SHIFT rather than GO). This replaces a strong claim about linguistic control over saccade extent with the more modest proposal that lexical and sublexical properties of a stimulus array as a whole influence refixation strategy ${ }^{\mathrm{vii}}$. A key function of within-word refixations, which are overwhelmingly right-going, is to change the visibility of potential parafoveal targets. Intra-word shifts in position thus act to modulate the rate of information acquisition across a span involving more than one word. Although factors determining the tension between STAY and SHIFT decisions are not well understood, Kennedy argues that the totality of parafoveal-on-foveal effects cannot be accounted for by a low-level influences over STAY and GO. Process-monitoring acts to maintain a roughly 
constant total time distributed over adjacent words primarily through its influence on the SHIFT decision (Kennedy, 1998, 2000a).

The present experiment was motivated by the fact that the large number of contradictory findings relating to parafoveal-on-foveal effects makes distinguishing between various processing models problematic. This is unsurprising, given that until recently, evidence for parafoveal-on-foveal cross-talk was negative (Carpenter \& Just, 1983; Henderson \& Ferreira, 1993, Rayner, Fischer \& Pollatsek, 1998). Carpenter and Just used linear regression to partition variance in gaze duration in normal reading between a number of measures, including length and word frequency and showed that features of word $n+1$ had negligible effects on fixation times on word $n$. However, since they also found no modulation of preview advantage, it is possible the regression technique was too insensitive to deal with the issue. In contrast, the study by Henderson and Ferreira, looking at the frequency of successive words embedded in short sentences, showed a clear preview effect but processing time on word $n$ was not significantly influenced by the frequency of word $n+1$. Unfortunately, in this study only the word frequency of successive words was manipulated, with no orthogonal variation in word-length or initial letter frequency (both properties which later work has shown to be crucial). The experiments reported by Rayner, Fischer and Pollatsek (1998) were designed to address another issue (the effect of inter-word spacing, but involved systematic manipulation of the frequency of particular target words. The duration of the fixation immediately preceding a given target word $\mathrm{N}$ was not systematically influenced by the frequency of word N. But no details are given of the length or frequency of word N-1 and the reported measure (in effect, the final fixation on $\mathrm{N}-1$ ) represented a mix of single and 'last of many' fixations. However, On the other hand, if it is to be argued that parafoveal-on-foveal interactions do occur routinely (and the brief summary above suggests this may be so), it must 
equally be accepted that there are an embarrassing number of inconsistencies in the obtained data. Low constraint in a parafoveal word's initial letters appears to increase or decrease foveal processing time, depending on parafoveal word frequency. Similarly, low-frequency parafoveal words may lead to an increase or to a decrease in foveal processing time, depending on such factors as the experimental task, the length of the relevant stimuli and the distribution of information within them. Given that lexical parafoveal effects appear so fugitive, it is puzzling that apparently robust pragmatic effects can be demonstrated (but in a direction not uniformly consistent with lexical effects). At least part of the explanation for these discrepancies may relate to control over the relevant experimental materials. The experiments summarised above rarely manipulated properties of the parafoveal target orthogonally. Furthermore, and perhaps critically, properties of the foveal stimulus, on which measurements were made, varied considerably between studies and were not always manipulated systematically. Schroyens et al (1999) employed a crossed design, simultaneously manipulating foveal and parafoveal word frequency, controlling for foveal length, but with no control for initial letter frequency; Underwood et al (2000) employed low frequency stimuli only; Inhoff et al (2000) manipulated foveal word frequency, but confounded it with parafoveal target frequency; Murray (1998) used frequency-matched items but did not control for the informativeness of initial letter sequences; Kennedy (1998) used only two short foveal stimuli, with multiple presentations; and Kennedy (2000a) employed only short, high frequency words. Few of these studies attempted orthogonal manipulation of initial letter constraint and word frequency, and there has been only one attempt to dissociate initial letter constraint and initial letter token frequency, or 'familiarity', also with somewhat inconsistent results (Kennedy, 1998). Finally, while the length of a parafoveal target word has been manipulated in some studies, no systematic attempts have been made to the effects of 
foveal word length. This is a surprising and critical omission, given the fact that refixation strategy within a given foveal stimulus is a primary determinant of measured gaze duration and refixations clearly constrain parafoveal processing, by influencing launch position (Kennison \& Clifton, 1995).

The present experiment was conducted with two broad objectives. The first was to replicate and extend the experiments reported in Kennedy (2000a) and confirm the existence of parafoveal-on-foveal effects under conditions of tight experimental control over physical, lexical, and sub-lexical properties of the manipulated materials. The word frequency of both foveal and parafoveal items was manipulated, together with the constraint (or 'informativeness') of the parafoveal word's initial three letters. Control over word length, as a factor influencing mutual processing interactions, was manipulated, for both foveal and parafoveal stimuli, over a range (5-letter versus 9-letter) where unambiguous measures of refixation strategy could be obtained. Predictions regarding variation in foveal length can be derived from the comment by Kennison and Clifton (1995) that 'the extent to which boundary [i.e. foveal word as defined here] and target word frequency effects can be observed on parafoveal preview benefit will largely be determined by whether the target word is viewed in parafoveal vision from the same distance across experimental conditions.' (p.78). This implies that parafoveal-on-foveal (if any) should interact with foveal word length. In summary, five factors were crossed in the design: the length and frequency of a defined foveal stimulus word, and the length, frequency and initial letter constraint of a parafoveal target word. A laboratory procedure was used, but one, which plausibly captured some features of eye movement, control typical of normal reading (a version of the 'Clothing Search Task' used by Schroyens et al, 1999, and Kennedy, 2000a). The experimental procedure is illustrated in Figure 1. After fixation of a contingent fixation marker, subjects saw a sequence of five 
words. The third and fourth words defined two critical items: the 'foveal' word (e.g. roule in Figure 1) and its associated 'parafoveal' target (e.g. motte in Figure 1). While the eyes were to the left of the space before the third word in a string of five, that word was masked ${ }^{\text {viii }}$. The experimental manipulations were restricted to these two critical words because, quite apart from the mechanisms of attention allocation, acuity constraints would appear to preclude powerful processing interactions involving more than two adjacent words.

Figure 1 about here

The second broad objective was to test specific predictions derived from the five models reviewed above (serial-sequential attention switching; pure parallel processing; distributed parallel processing; processing difficulty; and process monitoring). The classical attentionswitching model plainly predicts no parafoveal-on-foveal effects either on measures of timing or on saccade extent. Apart from direct parafoveal-on-foveal effects, pure and distributed parallel processing models can be distinguished by the form of trade-off, if any, between foveal and parafoveal processing: in the first case, spill-over effects are predicted, with a positive relation between foveal and parafoveal processing time; in the second case, the reverse should be found. However, neither model predicts 'inverted' effects, with parafoveal difficulty reflected in reduced foveal processing time. The process-monitoring model predicts parafoveal effects on refixation strategy, with processing success sustained by a mechanism optimising target visibility. This predicts both processing trade-offs and inverted effects when, for example, parafoveal difficulty triggers an early inter-word saccade. The processing difficulty hypothesis predicts no parafoveal-on-foveal effects on processing time, but effects 
on target landing position, with 'difficult' parafoveal stimuli associated with left-shifted initial fixation position.

\section{Method}

\section{Participants}

Thirty-six French-speaking undergraduate and postgraduate students of the University of Aix-en-Provence volunteered to participate in the study. Participants were not paid to take part. All had normal or corrected-to-normal vision. Some had participated in other eye tracking experiments, but none were aware of the research hypotheses in the present study.

\section{Materials and Design}

Table 1 about here

Illustrative examples of the experimental words are shown in Table 1. There were five factors in the design: the foveal word was either long (5-letters) or short (9-letters) and, at each length, high and low frequency items were chosen with reference to the FrenchLanguage Brulex database (Content, Mousty \& Radeau, 1990) with values, in words per million, as follows: short high frequency $=81.8$; short low frequency $=0.7$; long high frequency $=75.6$; long low frequency $=0.17$. Parafoveal target words were also either 5 or 9 letters in length and crossed with word frequency ( short high frequency $=343.06$; short low frequency $=1.51$; long high frequency $=95.90$; long low frequency $=0.35$, all values words per million) ${ }^{\mathrm{ix}}$. Each of these four sets were further split on the basis of the 'informativeness' of the initial three letters of individual words (Content \& Radeau, 1988). On average, fiveletter 'informative' parafoveal words shared their initial trigrams with 1.6 other five-letter words and 'uninformative' with 4.4 other five-letter words. The equivalent values for nine- 
letter parafoveal words were 2.3 and 9.2. The token frequency of the initial trigrams was controlled across the set of materials .

The experimental words were embedded into five-word strings, and invariably occupied positions 3 and 4 in the string. Words at position 2 in the string (i.e. just prior to the defined foveal stimulus word) were all four letters in length, providing a restricted 'launch space' prior to the first of the experimental items. The first and last words in the string were of roughly equivalent, and high, token frequency and varied between 5 and 8 letters in length. In addition to strings containing experimental items, there were 12 five-word strings each containing a single word describing an article of clothing, located across the set at all possible positions within the string. There were also 12 practice strings, one of which contained an article of clothing.

Four items sets were constructed, assigning different counterbalanced sets of 12 foveal words to the 8 conditions defined by the properties of parafoveal words. The 12 'Clothing word' strings were mixed randomly with these, making 108 strings in all. These were presented in different random sequences to each subject. Since all factors were manipulated within-subjects, the design was a split-plot with factors of Foveal Word Length, Foveal Word Frequency, Parafoveal Word Length, Parafoveal Word Frequency, and Parafoveal Word Informativeness. The particular allocation of sets of foveal words to a defined parafoveal condition was treated as a dummy factor in the analyses ${ }^{\mathrm{x}}$.

\section{Apparatus}

The materials were presented, in a non-interlaced mode, in white-on-black polarity on a monochrome monitor with a high-speed phosphor running at $100 \mathrm{~Hz}$ frame rate. The monitor was interfaced to a Control Systems Artist 1 graphics card mounted in an IBM compatible computer. The fixation marker and experimental materials were displayed using a high- 
resolution (8x16) monopitch font. At the viewing distance of approx $500 \mathrm{~mm}$, one character subtended approximately 0.3 degrees of visual angle. Masking was achieved by randomly relocating the pixels making up the constituent letters of a word. This procedure ensured that the average brightness of the displayed stimulus in its clear and masked versions was exactly matched. It was confirmed independently that unmasking invariably took place within a single screen refresh cycle.

Eye movements were recorded from the right eye using a Dr Bouis pupil-centre computation Oculometer interfaced to a 12-bit A-D device sampling X and Y position every 2 ms. This eye tracker has a resolution of better than 0.25 characters over the 60 -character calibrated range (Beauvillain \& Beauvillain, 1995). A dental wax bite bar and chin rest were used to minimise head movements. The eye movement recording system was calibrated prior to the presentation of each set of 3 experimental items. Viewing was binocular and horizontal eye position was recorded every five ms. Measures of fixation duration, fixation position, and intra- and inter-word saccade extent were computed off-line using statistical algorithms based on the effective resolution of the data for each individual subject, with respect to the obtained noise in a given data set. On this basis, the effective resolution of the eye-tracking equipment was better than 0.5 characters.

\section{Procedure}

On arrival, participants were asked to read a set of printed instructions for the experiment. Each trial began with the display of a fixation marker in the form of a small cross (+). When the computer detected stable fixation of this marker for at least $150 \mathrm{~ms}$ it changed to a colon (:) which was, after $500 \mathrm{~ms}$, replaced by the display of the five experimental words, each separated by a single space (as noted above, at this stage the foveal stimulus word at position 3 was masked). The fixation marker was located so that the initial fixation fell on the 
third letter of the first word in the string of five words. The instructions required participants to look at each word in turn and press a right-hand button if any of the displayed words was an article of clothing, otherwise a left-hand button was to be pressed. It was explained that articles of clothing appeared very rarely and that the task demanded care because the targets could be located at any position within a string.

Participants were initially given practice on the procedure and, once this had been mastered, a dental composition bite bar was prepared and the calibration technique demonstrated. This required the fixation of five points distributed evenly across the horizontal axis of the screen at the point where the experimental items were to be displayed. The calibration points were restricted to 60 character positions, a region less than the full screen width, to increase resolution.

\section{Results and Discussion}

The first measures to be reported relate to gaze duration on the first of the two experimental words (henceforth, the foveal word) as a function of both its own properties and those of the following word (henceforth, the parafoveal word). It will be recalled that the experimental procedure ensured that the foveal word was masked until the eyes moved beyond the space to its left. To simplify the treatment of a complex five-factor design the following analysis strategy has been followed. Since the experiment was in part intended as a replication of Kennedy (2000a), an initial analysis will be reported on the single quadrant of the design involving short, high frequency foveal words, allowing for direct comparison with the data of that earlier study. Following this, the experiment as a whole will be analysed.

Short, high frequency foveal stimuli

As noted above, the case where the foveal word was short and of high frequency, since this provides a direct comparison with the data, derived from English words, reported in 
Kennedy (2000a). Average foveal gaze duration in various conditions for this quadrant of the design, plotted as a function of properties of a parafoveal word, are shown in Figure 2. Gaze was notably longer overall than in the earlier study (436 ms, versus $270 \mathrm{~ms}$ and $295 \mathrm{~ms}$ in Experiments 1 and 2 respectively), but it must be borne in mind that the present task involved checking many more words and was, as a result, probably more difficult.

Fig 2 about here

Overall, gaze duration was longer when the parafoveal word was uninformative $($ Informative $=408 \mathrm{~ms}$, Uninformative $=470 \mathrm{~ms}), \mathrm{F} 1(1,32)=18.43, \mathrm{p}<0.001, \mathrm{~F} 2(1,16)=$ 20.987, $\mathrm{p}<0.001$. The obtained effect of the parafoveal word's frequency was inverted with respect to what might be expected for foveal inspection, (Low Frequency $=425 \mathrm{~ms}$; High Frequency $=453 \mathrm{~ms})$, but this difference only approached significance, F1 $(1,32)=3.66, \mathrm{p}=$ $0.06, \mathrm{~F} 2(1,16)=2.85, \mathrm{p}=0.1$. The effect of parafoveal word length was also nonsignificant, $($ Short $=431 \mathrm{~ms}$; Long $=446 \mathrm{~ms}, \mathrm{~F} 1(1,32)=2.05, \mathrm{~F} 2(1,16)=3.30, \mathrm{p}=0.09)$. The pattern of results confirms the presence of strong effects of the informativeness of the initial letters of a parafoveal word: gaze on a foveal word is longer when the parafoveal target is uninformative or 'redundant' (i.e. with low constraint in its letters). No interaction with parafoveal word length was found, but this may be a reflection of the fact that both foveal and parafoveal words varied in length in the present experiment, something which is discussed in detail below. Although not significant, it is noteworthy that the obtained effect of parafoveal word frequency was in an inverted direction, high frequency words being associated with longer, not shorter, foveal gaze duration. Figure 2 shows a good level of correspondence with the pattern of results reported in Kennedy (2000a). 


\section{Short foveal words}

Having dealt with the question of replication, we can now turn to the extension of the study to include simultaneous manipulation of the length and frequency of the foveal word. In fact, although the above analysis of a single quadrant of the overall design appears to resolve the conflict of data regarding sub-lexical properties of a parafoveal target and provides a useful comparison with earlier comparable materials and procedure ${ }^{\mathrm{xi}}$, it was not justified by statistical analysis of the design as a whole. An analysis of the complete data set revealed no significant five-way interaction, F1 $(1,32)=1.22 ; \mathrm{F} 2(1,64)=1.57$, but a significant highorder interactions involving between Foveal Length, Parafoveal Informativeness, Parafoveal Frequency, and Parafoveal Length, F1 $(1,32)=8.62, p=0.006 ; F 2(1,64)=7.61, p=0.008$ That is, there was no interaction specifically justifying separate treatment of short, high frequency, foveal stimuli (i.e. interactions involving foveal length and frequency). In fact, the obtained four-way interaction suggests that the length of the fixated foveal word strongly conditioned effects of the manipulated parafoveal properties, which is hardly surprising, given that word length plays an important role in determining refixation strategy. Consequently, separate analyses were carried out for each length of foveal word.

Fig 3 about here

Considering measures over the set of short foveal stimuli as a whole, gaze duration showed a significant main effect of the parafoveal word's informativeness (Uninformative $=$ $449 \mathrm{~ms}$, Informative $=429 \mathrm{~ms}), \mathrm{F} 1(1,32)=4.664, \mathrm{p}=0.04, \mathrm{~F} 2(1,32)=5.221, \mathrm{p}=0.03$ and $\mathrm{a}$ 
near-significant main effect of its word frequency, again in an unorthodox direction (Low Frequency $=428 \mathrm{~ms}$; High Frequency $=449 \mathrm{~ms}), \mathrm{F} 1(1,32)=5.56, \mathrm{p}=0.02, \mathrm{~F} 2(1,32)=3.39$, $\mathrm{p}=0.07)$. However, these two factors interacted strongly, $\mathrm{F} 1(1,32)=8.82, \mathrm{p}=0.006, \mathrm{~F} 2$ $(1,32)=7.90, p=0.008$. The form of the interaction is shown in Figure 3, which reveals a significant (inverted) effect of parafoveal word frequency, restricted to cases where words possessed high constraint (informative) initial letters, F1 $(1,32)=16.71$, p $<0.001$, F2 $(1,16)$ $=11.99, \mathrm{p}=0.003$. A significant effect of the informativeness of the parafoveal word's initial letters was restricted to low frequency items, F1 $(1,32)=14.76, \mathrm{p}<0.001, \mathrm{~F} 2(1,16)=13.56$, $\mathrm{p}=0.002$. No other contrasts were significant, all F1 and F2 $<1$.

Fig 4 about here

To determine whether the modulation of gaze duration by properties of the parafoveal word was primarily a reflection of changes in the number of fixations or in their duration, analyses of refixation rate on the foveal word were carried out. The relevant data, based on right-going refixations which comprised over 95 percent of all refixations, are shown in Figure 4. Although the foveal stimulus was short, and its refixation might appear unnecessary, or even dysfunctional, it obvious that the variation in gaze duration in Figure 3 is readily accounted for by changes in foveal refixation rate. The relevant Parafoveal Word Informativeness x Parafoveal Word Frequency interaction was significant, F1 $(1,32)=5.99$, p $=0.02, \mathrm{~F} 2(1,32)=17.79, \mathrm{p}<0.001:$ as in Figure 3, the effect of Parafoveal Word Frequency was restricted to informative parafoveal words, with a highly significant tendency to refixate a foveal word when the parafoveal target was a high frequency word, $F 1(1,32)=6.07, p=0.02$, F2 $(1,16)=25.02, p<0.001$. Similarly, the effect of the parafoveal word's informativeness 
was restricted to low frequency items, $\mathrm{F} 1(1,32)=5.78, \mathrm{p}=0.007, \mathrm{~F} 2(1,16)=9.69, \mathrm{p}=$ 0.007. No other contrasts in Figure 4 were significant. It may be concluded that, for short words, properties of a parafoveal word influence foveal refixation rate. More specifically, there is relatively low rate of foveal refixation associated with low frequency parafoveal words possessing highly constrained initial letters.

Figure 2 (and the comparable data of Kennedy, 2000a, Experiment 2) invited an interpretation in terms of a lengthened gaze associated with uninformative parafoveal items, but the significant interactions present in Figures 3 and 4 point to an alternative conclusion. A foveal word is much less likely to be refixated (with the result that gaze duration is significantly shorter) when a parafoveal target is simultaneously of low frequency and contains initial letters with a low (type) frequency of occurrence. An interaction of this form, is known to occur under conditions of foveal inspection (Owswitz, 1963; Broadbent \& Gregory,1968; Pynte \& Masselot, 1980; Rice \& Robinson,1975). These studies showed that, for low frequency words, those with rare initial letters are actually recognised faster than those with common initial letters. This difference is not found for high frequency words. The apparent paradox can be explained by noting that rare initial letters are 'informative' in the sense that they are more effective in contacting lexical representations, something which may provide a relative advantage for low frequency words. Such a sub-lexical route will be less advantageous for high frequency words because of the increased likelihood in that case that a lexical route will win the race to identification. The question arises, therefore, as to whether the parallel between the present data and the results obtained with foveal inspection forces the conclusion that participants in the present experiment achieved lexical access on the parafoveal target word. An immediate problem is that this would not account for the fact that the highly significant effect of word frequency for parafoveal items having informative initial 
letters was in an unorthodox direction (i.e. shorter gaze associated with low frequency items). An alternative possibility is that reduced foveal inspection time could be interpreted as an index of parafoveal difficulty, rather than foveal success. Given that a low refixation rate is equivalent to an early inter-word saccade, it might be argued that the configuration of letters representing informative parafoveal targets in some sense 'attracted' a premature saccade. However, since initial letter 'difficulty' was crossed in the design and the same effect was not found for high frequency parafoveal words, the question arises as to why this process of sublexical 'attraction' was only operative for low frequency words. The most plausible answer is that all parafoveal words were identified (albeit after shifting fixation position in the foveal word), except for those defined as low frequency and informative. The initial letters of this set of words, are (by definition) more likely to activate lexical candidates and may, as a result, become the target of an early saccade. The fact that an equivalent pattern does not occur with high frequency parafoveal targets is simply because that set of words could be processed at a lexical level. Doré \& Beauvillain (1997) offer a similar account in terms of a race between lexical and sub-lexical processes to account for their observations on the initial landing position of saccades directed towards words with regular or irregular initial letter sequences. When a saccade is artificially delayed (thus allowing more time for parafoveal processing) there is no difference in its extent as a function of initial letter sequence regularity, but for normal-latency saccades, Doré and Beauvillain showed that landing position is deviated towards the beginning of words with irregular letters.

The pattern of data for this set of short foveal words suggest that three levels of parafoveal processing must be distinguished: (i) an orthographic level, relating to a particular configuration of initial letters; (ii) a candidate activation level, relating to the power of a particular letter sequence to activate a greater or lesser number of lexical candidates; and (iii) 
a true lexical level, relating to word identification. There is some evidence that processing at level (i) may lead to a global modulation of inter-word saccade extent (Hyönä, 1995; Hyönä \& Pollatsek, 1998) and this is considered further below. Depending on the task, (iii) may lead to word-skipping. The interest in the present data relates to level (ii). It is the sub-lexical activation of a candidate set which is signalled to a process-monitoring mechanism as indicating a potentially interesting landing site on a parafoveal target.

Fig 5 about here

One remaining significant interaction must be discussed, involving Parafoveal Word Informativeness and the Word Frequency of the foveal item itself, F1 $(1,32)=15.58, \mathrm{p}<$ $0.001, \mathrm{~F} 2(1,16)=14.00, \mathrm{p}=0.001$ (see Figure 5). Obviously, for this set of short words, foveal load (as indexed by word frequency) strongly modulated the effects of the parafoveal target word. No effects were found for high load (i.e. low frequency) foveal items, F1 = 2.62, F2 $<1$. Significant effects of parafoveal word informativeness on foveal gaze were restricted to cases where foveal load was low (i.e. high frequency), F1 $(1,32)=18.43, \mathrm{p}=0.003, \mathrm{~F} 2$ $(1,16)=20.99, \mathrm{p}<0.001$. When the parafoveal word was informative, the obtained foveal frequency effect was in the usual direction, with longer gaze on low frequency words, F1 $(1,32)=9.00, p=0.005, F 2(1,16)=8.96, p=0.008$. However, when the parafoveal word's initial letters were uninformative the frequency effect was significantly reversed, F1 $(1,32)=$ $8.04, \mathrm{p}=0.008, \mathrm{~F} 2(1,16)=5.51, \mathrm{p}=0.03$

Fig 6 about here 
Figure 6 confirms that the modulation of foveal gaze shown in Figure 5 is largely a function of changes in refixation rate. There was a significant Parafoveal Word Informativeness x Foveal Word Frequency interaction, F1 $(1,32)=21.07, \mathrm{p}<0.001$, F2 $(1,32)$ $=21.50, \mathrm{p}<0.001$. In this case, however, and in contrast with data shown in Figure 5, the effect of Parafoveal Word Informativeness ran significantly in opposite directions for high and low frequency foveal words (High Frequency Word 1, F1 $(1,32)=14.29, \mathrm{p}<0.001, \mathrm{~F} 2$ $(1,16)=13.39, p=0.002 ;$ Low Frequency Word $1, F 1=3.79, p=0.06 . F 2(1,16)=8.74, p=$ 0.009). Overall, there was a weak tendency for low frequency foveal words to be refixated more than high frequency (High Frequency Word $1=0.38$; Low Frequency $=0.42$, F1 $(1,32)$ $=2.61, \mathrm{p}=0.11, \mathrm{~F} 2(1,32)=2.00, \mathrm{p}=0.16)$, but this was strongly the case in the presence of parafoveal targets with informative (i.e. relatively constraining) initial letters, F1 $(1,32)=$ $6.07, \mathrm{p}=0.02, \mathrm{~F} 2(1,16)=25.02, \mathrm{p}<0.001$. The apparent difference in the opposite direction for parafoveal words with uninformative initial letters was not statistically reliable, F1 $(1,32)$ $=3.45, \mathrm{p}=0.07, \mathrm{~F} 2(1,16)=2.27, \mathrm{p}=0.15$

Considering the pattern of results as a whole, we conclude that the rather paradoxical effects arising from changes in parafoveal word frequency stem from a tendency not to refixate a foveal word when the word about to be fixated cannot be identified, but its initial letters, nonetheless, are constraining enough to yield a relatively small pool of lexical candidates. This implies, of course, that the relevant properties (i.e. at least word frequency and constraint) are available during a given foveal inspection. In other conditions, the default strategy takes the form of a tendency to execute within-word shifts, almost always resulting in a fixation position closer to a potential target, which becomes more visible as a result. This inevitably also leads to an increase in foveal gaze. Changes in refixation rate must be seen as 
superimposed on effects produced directly by properties of the foveal word itself and it is this which leads to the interaction seen in Figure 6.

The data confirm the well-documented fact that readers can sometimes identify words (and in particular short words) in the parafovea. But this is not simply the source of a preview advantage: the processing is reflected in current foveal inspection time. Both parafoveal and foveal word recognition appears to involve a race between lexical and sub-lexical routes, with the consequence that certain parafoveal targets are associated with an early inter-word saccade. It is this which leads to the apparently paradoxical reversal in the effect of parafoveal word frequency. Taken as a whole, the results are patently incompatible with the serial sequential attention allocation model. Predictions with regard to tradeoffs between foveal and parafoveal words must wait on analyses of behaviour on the parafoveal word itself, but two aspects of the data already present difficulties for the pure parallel processing account. First, low frequency parafoveal words should increase global load, and hence lengthen foveal gaze rather than shorten it. Second, low frequency foveal words, by increasing processing time, should increase the opportunity for parafoveal processing and properties of a parafoveal word might be expected to have a greater effect in this condition, whereas the reverse was found. This latter outcome is more consistent with a distributed parallel processing account, but this too cannot easily deal with the 'inverted' effects of parafoveal word frequency. A distributed processing model certainly predicts a negative relationship between foveal and parafoveal inspection time, but this falls short of explaining how parafoveal difficulty comes to modulate foveal processing time in the first place. In this respect, the notion of a processing monitoring mechanism provides a more satisfactory account. 
Fig 7 about here

The evidence of parafoveal-on-foveal effects on gaze duration is clearly inconsistent with the prediction of a null effect on timing decisions derived from the Processing Difficulty Hypothesis, but to examine the influence of parafoveal initial letter constraint on targeting behaviour, analyses were carried out on initial landing position on the parafoveal word. The relevant data are shown in Figure 7. Overall, there was a highly significant interaction between the length and the informativeness of the parafoveal target word, F1 $(1,32)=11.88, p$ $<0.001, \mathrm{~F} 2(1,16)=13.652, \mathrm{p}=0.001$ and separate analyses were carried out for short and long parafoveal words respectively. For short words, landing position deviated 0.32 characters to the left (i.e. nearer to the beginning of the word) for parafoveal words with informative initial letters, $F 1(1,32)=6.33, p=0.02, F 2(1,16)=9.92, p=0.006$. Since these words probably satisfy the definition of 'unusual initial letter configuration' adopted by Hyönä (Hyönä, 1995; Hyönä \& Pollatsek, 1998, 2000), the direction of the obtained effect is as predicted by the processing difficulty hypothesis. Similarly, although the difference in landing position as a function of parafoveal word frequency was not reliable by items, F1 $(1,32)=9.02, \mathrm{p}=0.02, \mathrm{~F} 2(1,16)=2.74, \mathrm{p}=0.1$, it was in the predicted direction, with low frequency items associated with a left-shift in landing position. Saccades directed towards words with informative initial letters appear to be deviated to the left (see also Doré \& Beauvillain, 1997). Nonetheless, before this outcome is seen as strongly supportive of the processing difficulty hypothesis, three significant caveats must be entered. First, changes in average landing position cannot derive from a modulation in the rate of skipping, since the critical experimental words were virtually never skipped in the present task ${ }^{\mathrm{xii}}$. Second, to anticipate analyses which are presented in a later section, the data for long parafoveal targets, 
show a completely different pattern, with a tendency to land further to the right for words with informative initial letters. Finally, it is puzzling that the interactions shown in the analyses of gaze and refixation rate are not reflected in analyses of landing position. The balance of evidence (including the indication of a frequency effect on landing position) suggests that short parafoveal words may have been identified as a result of foveal word refixation strategy, specifically triggered by the extraction of lexical and sublexical information from the parafovea. If this is the case, the obtained modulation of landing position on the parafoveal word may actually be a reflection of consequential changes in launch position from the foveal word ${ }^{\text {xiii }}$.

These analyses of data for short foveal stimulus words represent a serious challenge to any model demanding serial sequential allocation of attention, including hybrid models postulating parafoveal modulation of a gradient of attention deployed serially over two or more words. The most parsimonious interpretation of the data is that the rate of acquisition of parafoveal information influences whether or not a currently fixated word will be refixated. The principal difficulty with such an explanation is that it appears implausible: the refixation of short words in this context seems dysfunctional. Since shifts within a five-word foveal stimulus, whether or not these are triggered by properties of a parafoveal word, produce only modest changes in its visibility, the influence of refixation strategy on processing success can better be explored through an analysis of long foveal stimuli, where refixation typically plays a role in identification. This is dealt with in the following section.

Long foveal words

Fig 8 about here 
When the foveal word undergoing fixation was long, the length of the parafoveal word itself had a much greater effect on the obtained results. This is to be expected since, when both words were long, the distance from the point of initial fixation on the foveal stimulus to the centre of the parafoveal word could be 12 characters or more. The drop in acuity over this range makes identification of a long word unlikely, and might, in some cases, even inhibit the identification of its initial letters. For this reason, it is unsurprising to find a highly significant three-way interaction between the length of the parafoveal word and its informativeness and frequency, F1 $(1,32)=14.28, \mathrm{p}<0.001, \mathrm{~F} 2(1,16)=10.64, \mathrm{p}=0.003($ see Figure 8$)$. When both foveal and parafoveal words were long, there were no significant effects of either parafoveal informativeness or frequency on foveal gaze, and no interaction (all $\mathrm{F} 1<1$; all F2 $<2.0)$. When the parafoveal word was short, however, an interaction between parafoveal informativeness and frequency was found, F1 $(1,32)=24.06, \mathrm{p}<0.001, \mathrm{~F} 2(1,16)=10.70, \mathrm{p}$ $=0.005$. This is, of course, the statistical interaction illustrated in Figure 3 for the equivalent set of short foveal words, but its form is strikingly different. There was a significant effect of Informativeness for low frequency parafoveal words, $\mathrm{F} 1(1,32)=16.55, \mathrm{p}<0.001, \mathrm{~F} 2(1,8)=$ $17.68, \mathrm{p}=0.003$, but not for high frequency words, $\mathrm{F} 1(1,342)=2.89, \mathrm{~F} 2<1$. The (reversed) frequency effect for parafoveal words with uninformative initial letters was significant, F1 $(1,32)=9.64, p=0.004, F 2(1,8)=6.40, p=0.03$ and the effect in the opposite direction for informative initial letters was significant by subjects and narrowly missed significance by items, F1 $(1,32)=14.44, \mathrm{p}<0.001, \mathrm{~F} 2(1,8)=4.87, \mathrm{p}=0.06$

Fig 9 about here 
Before attempting to account for the remarkable contrast in the pattern of significant effects in Figures 3 and 8, it is helpful to look at the degree to which variation in gaze duration on long foveal words reflected changes in refixation rate. Figure 9 shows (rightgoing) refixation probability. The parallel between these data and the pattern evident in Figures 8 is obvious: as in the case of short foveal stimuli, variation in foveal gaze duration was largely determined by changes in refixation rate. There was a significant three-way interaction between the Informativeness, Frequency and Length of the parafoveal target word, $\mathrm{F} 1(1,32)=8.94, \mathrm{p}=0.005, \mathrm{~F} 2(1,32)=7.25, \mathrm{p}=0.01$. As with the analysis of gaze duration, the Informativeness x Frequency interaction was not significant for long parafoveal words, F1 $<1, \mathrm{~F} 2(1,16)=2.04$, but highly significant for short targets, F1 $(1,32)=16.69, \mathrm{p}<0.001, \mathrm{~F} 2$ $(1,16)=21.73, \mathrm{p}<0.001$. Gaze on long foveal stimuli is obviously driven by changes in refixation rate, but the rate of refixation itself was also sensitive to the length of the parafoveal target word. When this was long, foveal refixation rate, at around 0.4 , was relatively unaffected by its properties. However, when the parafoveal target was short (and presumably more visible), foveal refixation strategy was strongly influenced by the initial letter configuration in the parafovea. An informative letter string (which viewed from a remote site may simply have been categorised as an unusual configuration) raised refixation rate to around 0.6 (i.e. more SHIFT responses) whereas an uninformative parafoveal string lowered it to around 0.3 (i.e. more GO responses).

It will be recalled that Figure 3 was interpreted as suggesting an early exit saccade when a parafoveal word was of low frequency and had highly constraining initial letters. Analyses of landing position on the parafoveal word suggested that this early GO decision was targeted towards the crucial initial letter sequence. That is, a saccade was launched towards the 
sequence of letters yielding a relatively small pool of 'candidate' lexical items. This was not the case for the long words illustrated in Figure 8, since the shortest gaze duration and lowest refixation rate was associated with (short) parafoveal words having initial letters which were relatively uninformative. But it should be borne in mind that refixation of a long foveal word is, in any case, a highly probable event, simply because more than one fixation may be may be required for its identification ${ }^{\mathrm{xiv}}$. Thus, in the present task there are at least two reasons why an intra-word saccade might be executed. The first is to identify the foveal word itself (i.e. an orthodox refixation, unrelated to parafoveal processing); the second is as a response to the kind of parafoveal processing demands demonstrated for short foveal stimuli (i.e. a SHIFT). This observation poses rather severe problems of interpretation since, in both cases, refixation will act to make the parafoveal word more visible and change the probability that its processing will have an influence on foveal inspection time. Although it is plausible that factors which led to an early inter-word saccade in the case of a short foveal stimulus may have led to an early intra-word saccade with a long stimulus, it is in principle impossible to know. All that can be said is that, in a significant proportion of cases, the measure of gaze in Figure 8 was derived from time spent in the second half of the foveal word. Foveal identification and parafoveal visibility are necessarily confounded (Kennison \& Clifton, 1995) and refixation rate on long stimuli may be modulated simultaneously (and differentially) by properties of both foveal and parafoveal stimuli, making interpretation of whole-word gaze measures very problematic. One solution to this problem, first adopted by Pynte et al (1991), is to partition total gaze on long words into two 'sub-gaze' elements, and to carry out separate analyses on the data deriving from first and second halves of the foveal stimuli ${ }^{\mathrm{xv}}$.

First-half sub-gaze on long foveal words 
Fig 10 about here

Mean sub-gaze duration on the first half of long words is shown in Figure 10. There was a significant main effect of Parafoveal Word Informativeness (Informative $=215 \mathrm{~ms}$,

Uninformative $=176 \mathrm{~ms}), \mathrm{F} 1,(1,32)=17.01, \mathrm{p}=0.0005, \mathrm{~F} 2(1,32)=16.57, \mathrm{p}=0.0005$ and $\mathrm{a}$ significant Informativeness x Frequency interaction, F1 $(1,32)=12.19, \mathrm{p}=0.002, \mathrm{~F} 2(1,32)=$ 10.04, $\mathrm{p}=0.004$. The three-way interaction between the Informativeness, Frequency and Length of the parafoveal word narrowly missed significance in the by-items analysis, F1 $(1,32)=4.16, p=0.04, F 2(1,32)=3.28, p=0.07$. Separate analyses for each length, showed a main effect of Informativeness for long parafoveal targets, F1 $(1,32)=8.67, p=0.006, F 2$ $(1,16)=5.09, \mathrm{p}=0.04$ and no interaction with Frequency, F1 $=1.00, \mathrm{~F} 2<1$. In the case of short items, there was a significant Informativeness $x$ Frequency interaction, F1 $(1,32)=$ $14.88, \mathrm{p}=0.008, \mathrm{~F} 2(1,16)=0.002$, with the effect of Informativeness confined to low frequency parafoveal words, F1 $(1,32)=20.77, \mathrm{p}<0.001, \mathrm{~F} 2(1,8)=4.52, \mathrm{p}=0.06$.

Fig 11 about here

There was also a highly significant interaction between the informativeness of the parafoveal word and the frequency of the foveal stimulus, F1 $(1,32)=21.54, \mathrm{p}<0.001, \mathrm{~F} 2$ $(1,32)=18.51, \mathrm{p}<0.001$, and a near-significant three-way interaction involving the frequency of the foveal stimulus and the informativeness and frequency of the parafoveal word, F1 $(1,32)=3.79, p=0.06, F 2(1,32)=4.13, p=0.04$. The form of this is shown in Figure 11 . 
Comparisons between Figures 10 and 11 suggest that the modulation of total gaze shown in Figures 8 and 9 is driven primarily by the time spent in the first half of the foveal stimulus. These data are not easy to interpret because there were insufficient cases reliably to distinguish single fixations on the whole word (located in the first half) and instances where measured sub-gaze reflected the duration of the first of one or more fixations. Nonetheless, the most obvious interpretation is that the condition associated with an increased number of inter-word saccades for short foveal stimuli (i.e. a low frequency parafoveal target with informative initial letters) is associated with an increased number of intra-word saccades when the parafoveal word is more remote. Manipulating the informativeness of the initial letters of a target word is likely to have different effects depending on whether or not the word as a whole is potentially capable of being identified. For low-frequency words viewed from a remote site (i.e. items which are unlikely to be identified) an informative initial letter sequence may simply be categorised as a 'difficult' orthographic cluster and, in terms of the three processing levels identified in the case of short foveal stimuli, such a configuration is likely to increase refixation rate rather than initiate an early inter-word saccade. Thus, if the function of these intra-word saccades is to improve the visibility of a target, to facilitate identification, the data for two sets of data may be less irreconcilable than at first appeared. In fact, two predictions can be generated. First, parafoveal influence on gaze on the second half of long foveal stimuli should be equivalent to that found for short, high-frequency foveal stimuli. This is because (i) a launch position much closer to the parafoveal stimulus makes its visibility comparable to that obtaining for short foveal stimuli, and (ii) prior fixation on the foveal word (and possibly even its prior identification) will act to reduce foveal load. The second prediction derives from the conjecture that a primary function of within word shifts is to optimise parafoveal processing. If this is the case, landing position on the parafoveal word 
following short and long foveal stimuli cases should be roughly equivalent, regardless of the differences in gaze for short and long foveal stimuli.

Second-half sub-gaze on long foveal words

Fig 12 about here

The equivalent data set derived from sub-gaze in the second half of the foveal stimulus are shown in Figure 12. They are plotted as a function of the variables in Figure 10 for comparison purposes only, because analyses showed only a single significant effect of Parafoveal Word Informativeness (Informative $=226$, Uninformative $=255)$, F1 $(1,32)=$ $6.95, p=0.01, F 2(1,32)=6.86, p=0.01$. The parallel with Figure 2 is striking: when the parafoveal stimulus is relatively close and foveal load is low, gaze is modulated by the informativeness of the initial letters of a parafoveal word, with an earlier inter-word saccade when these exhibit high constraint. Among other things, this analysis clarifies why parafoveal-on-foveal effects may be ubiquitous, yet difficult to demonstrate, and why reversals in the direction of obtained effects of parafoveal initial letter constraint might occur if foveal word length is not controlled.

It will be recalled that a crucial prediction relating to landing position on the parafoveal word was that this should show the same modulation with parafoveal properties for long and short foveal stimuli. The relevant data are shown in Figure 13, which is to be compared with Figure 7. In general, the two data sets show remarkable similarity. Analysis of variance reveals the same interaction between the informativeness and length of the parafoveal word, $\mathrm{F} 1(1,32)=13.29, \mathrm{p}=0.001, \mathrm{~F} 2(1,32)=13.652, \mathrm{p}=0.004$. There was a highly significant 
main effect of Parafoveal word Informativeness for short items, of about the same size $(0.38$ characters) and in the same direction as that found for short foveal stimuli, F1 $(1,32)=9.82$, $p$ $=0.004, \mathrm{~F} 2(1,16)=9.92, \mathrm{p}<0.006$. That is, consistent with the Processing Difficulty Hypothesis, landing position is deviated to the left for parafoveal words with more 'difficult' initial letters. Interestingly, the apparent interaction between Informativeness and Frequency in the case of long parafoveal words was also significant, $F 1(1,32)=4.32, p=0.04, F 2(1,16)$ $=12.75, \mathrm{p}=0.003$. Such a modulation in landing position in the absence of effects on inspection time is consistent with the Processing Difficulty Hypothesis, but the direction of the shift in landing position is not.

Fig 13 about here

\section{Parafoveal word analyses}

Analyses of gaze duration on the parafoveal target word serve two specific purposes. First, given the paradoxically reversed effects of parafoveal word frequency on foveal gaze, it is necessary to verify that parafoveal words exhibited relatively normal frequency effects when directly fixated (i.e. that the outcome was not a result of some peculiarity of the particular stimuli). Second, and more importantly, gaze duration on the parafoveal target word can be used to examine spill-over effects and trade-offs in processing time between foveal and parafoveal stimuli. To provide comparability with the data on the foveal word, separate analyses were carried out as a function of foveal length. Addressing first the question of frequency effects, in the case of parafoveal words examined following a short foveal word, gaze duration was significantly longer on low frequency items (Low Frequency 
$=461 \mathrm{~ms} ;$ High Frequency $=429 \mathrm{~ms}), \mathrm{F}(1,32)=6.76, \mathrm{p}=0.013 ; \mathrm{F} 2(1,32)=11.63, \mathrm{p}=$

0.002. In the case of parafoveal words following a long foveal word, the frequency effect was in the same orthodox direction (Low Frequency $=451 \mathrm{~ms}$; High Frequency $=433 \mathrm{~ms}$ ), but just failed to achieve significance, $F(1,32)=3.34, p=0.07 ; F 2(1,32)=3.62, p=0.06$. Taken together, these results demonstrate that the apparently inverted effects of parafoveal word frequency found in some measures of foveal gaze did not stem from any intrinsic peculiarities of the materials used a parafoveal stimuli.

Fig 14 about here

With regard to the question of a processing trade-off between the two successive items, when the foveal word was short, the effect of initial letter constraint on parafoveal gaze $($ Uninformative $=438 \mathrm{~ms}$, Informative $=457 \mathrm{~ms}), \mathrm{F} 1(1,32)=5.95, \mathrm{p}=0.02, \mathrm{~F} 2(1,32)=$ $2.46, p=0.12$, is effectively the reverse of the significant effects found for foveal gaze (compare Figure 14 and Figure 3). Equally, as noted above, the significant effect of the parafoveal frequency was the reverse of that found for the measure of foveal gaze. Measured over the two stimulus words combined, the effect of Parafoveal Word Informativeness was effectively zero (Uninformative $=441 \mathrm{~ms}$, Informative $=443 \mathrm{~ms}$ ) and the effect of Frequency was very small $($ Low Frequency $=445$ ms; High Frequency $=439 \mathrm{~ms})$ : neither effect approached significance, all F1 and F2 <1. In the case of long foveal stimuli, it should be recalled that Figure 8 showed no parafoveal effects for long parafoveal targets. It is sensible, therefore, to restrict the search for possible trade-offs to cases where the parafoveal target was short. The relevant data are shown in the left panel of Figure 15, which should be compared with the equivalent data in Figure 8. The pattern of data again shows evidence of a processing 
trade-off, with no effects of either frequency or informativeness in a combined analyses over Words 1 and 2, all $\mathrm{F} 1$ and $\mathrm{F} 2<1$.

Fig 15 about here

\section{GENERAL DISCUSSION}

Before attempting to relate the results in detail to the models and hypotheses outlined in the Introduction it is reasonable to ask how far the task employed here can be seen as an analogue of normal reading. Participants read through short lists of otherwise unconnected words, looking for rare instances of a particular category and it may be argued that this is more like a search process than like reading for meaning. The attentional span is larger in visual search tasks than in reading, for example, even extending below the fixated line when participants scan for defined letter targets, Prinz, 1984; Pollatsek, Raney, LaGasse \& Rayner, 1993). It is possible, therefore, that parafoveal-on-foveal effects arise because, on a given fixation, information becomes available from sites much more remote than found in normal reading. But even if this were so, it would be equally damaging to an attention-switching model, because the relevant issue is not the distance over which parafoveal information is available, but whether its influence extends to the current foveal fixation. In any case, the task used in the present study could not be charactersied a a straightforward visual search: it could not be executed unless participants accessed the meaning of the inspected words. In fact, the most commonly cited characteristic of a search process is the absence of a measurable frequency effect in the latter (Rayner \& Raney, 1995) and the data in the present experiment, with 
respect to both foveal and parafoveal words, are replete with evidence of strong frequency effects. To this extent the task quite clearly taps into lexical processes typical of normal reading. A possible counter to this is found in the study by Rayner and Fischer (1996), which employed an ingenious comparison involving identical words but different tasks. Fixations were generally much longer in search, compared to reading. Since gaze durations in the present experiment was generally long, some caution is called for in extrapolating from the results to reading in general. They should perhaps be seen as providing convergent data on 'continuous visual word processing', an initial step in a multi-task approach to reading, which is, in any case a skill involving many inter-linked components (see Grainger, 2000, for a discussion). Different performance measures and tasks each have peculiar strengths and weaknesses (Inhoff \& Radach, 1998) and the unique advantage of small-scale laboratory studies involving isolated words, or short strings of words, is the fact that orthogonal control is possible over the relevant variables, something which would be virtually impossible in an a study involving normal reading for comprehension. It should also be noted that several of the studies cited in the Introduction as showing evidence of parafoveal-on-foveal effects employed relatively normal reading tasks. Thus, while some of the effects reported in the present study have yet to be demonstrated in normal reading, others have been demonstrated, and it seems increasingly unlikely that parafoveal-on-foveal interactions are so highly taskspecific as to be essentially artifactual (see Kennedy, 2000a, for further discussion).

To consider the where decision first, the serial sequential model of eye movement control generates a rather confusing picture when dealing with possible parafoveal influences over saccade extent or initial landing position. If, as in the original Morrison formulation, an interword eye movement and an attentional switch are programmed at the same time, parafoveal properties (other than length) cannot influence saccade control. Similarly, if an eye 
movement is programmed following an initial foveal 'familiarity check', as in the Reichle et al model, lexical or sub-lexical properties of words in the parafovea should not affect saccade extent. But both formulations have a bearing on saccade control since they predict wordskipping effects, based on lexical identification of an 'easy' parafoveal word. In this regard the assumption of a strictly serial sequential process appears to have been relaxed for the where control decision, if not for the when decision (see also Rayner, Sereno \& Raney, 1996). Unfortunately, predicted effects on saccade programming from a parallel processing account are also somewhat confused and empirical evidence has not yet settled the question. For example, Underwood, Clews and Everatt (1990) provide evidence of semantic effects exerted from the parafovea over initial landing position, but this has proved difficult to replicate and the effect may either be very small or possibly arise as an artifact of particular materials (Rayner \& Morris, 1992; Radach \& Kempe, 1993). On the other hand, as noted above, there is a growing body of evidence supporting parafoveal orthographic effects on initial landing position (Hyönä, 1995; Hyönä \& Pollatsek, 1998, 2000; Vonk, Radach \& van Rijn, 2000) and suggesting that initial landing position is shifted about one third of a character on average to the left in words with constraining initial letters. With regard to short parafoveal words, Figures 7 and 13 confirm the presence of this small left shift in the landing position of saccades directed towards words with informative initial letters. However, this provides only limited support for the Processing Difficulty Hypothesis, because effects on landing position in the present experiment arose primarily as a consequence of shifts in launch position, driven by parafoveal effects on refixation strategy. In the case of long parafoveal words, there is obviously no evidence of a systematic left shift associated with informative initial letters, but the analysis of eye movements to and from long words present particular problems of analysis because of the need to distinguish genuine intra-word saccades from inter-word saccades 
falling short of their intended target. As an attempt to address this question an analysis was carried out of initial saccade extent from the foveal word, regardless of whether landing position fell within the foveal or parafoveal word. Interestingly, saccade extent was strongly influenced by properties of the foveal word itself, with a significant interaction between Parafoveal Word Informativeness and Foveal Length and Frequency, F1 $(1,32)=4.37, \mathrm{p}=$ $0.04, \mathrm{~F} 2(1,64)=5.56, \mathrm{p}=0.02($ see Figure 16$)$. With one exception, initial saccades were shorter in the presence of parafoveal words with informative initial letters, the exception relating to the case of short, high frequency, foveal words, where saccades to informative initial letters were actually longer. A possible explanation for this can be seen in the data for the equivalent set of parafoveal words in Figure 6. These data confirming that any obtained left-shift in landing position is largely determined by an increased number of refixations (i.e. a right-shift in launch position).

Fig 16 about here

Turning to the when decision, of the five models and hypotheses outlined in the Introduction, serial-sequential attention allocation and processing difficulty predict no parafoveal-on-foveal effects on the timing of eye movement control. The data presented here manifestly disconfirm this prediction. Pure parallel processing predicts effects in the opposite direction from those reported here: it is not the case that parafoveal processing increases with longer foveal inspection time. Distributed parallel processing predicts the obtained trade-offs between foveal and parafoveal inspection time, but has difficulty accounting for the effects of parafoveal word frequency and length on foveal inspection time. Variation in refixation rate is not a specific prediction of either parallel model. Process 
monitoring, involving a mechanism sensitive to processing success across combined foveal and parafoveal stimuli remains the only plausible account for a regular pattern in the obtained data (for example, Figure 3) where a single cell in a two-by-two data matrix differs from the other three, which do not differ among themselves. When foveal load is relatively low and the next word to be processed is short, it is likely to be identified. That is, if the rate of acquisition of information across the span (combining foveal and parafoveal letter sequences) is high, parafoveal identification will occur as a result of a within-word shift in position on a foveal stimulus. When the rate of acquisition of information suggests that a target requires processing at an orthographic level an 'early' inter-word saccade occurs with a landing position deviated towards critical defining letter sequences. For long targets, parafoveal lexical identification in the absence of refixation is improbable. However, sub-lexical properties of a parafoveal target exert an influence on the probability that the currently fixated word will be refixated, with a higher rate of refixation associated with low-frequency parafoveal targets possessing highly constraining initial letters. The function of systematic shifts in position within the foveal word is to change the visibility of the parafoveal word, with identical effects of initial letter constraint on landing position for both long and short targets.

We make no claim to originality in proposing a form of process monitoring. This class of model has a long history in experimental psychology (Shallice, 1964) and, indeed, played a role in early theories of eye movement control (Rayner \& McConkie, 1976; Rayner, 1977). The reasons for its decline probably relates to the failure of simple 'gain control' models to account for the eye movement data deriving from improved measurement techniques which became available in the 1970s, together with the success of inherently 'intermittent' models such as that of Morrison (see Rayner \& Pollatsek, 1989 for a review). Albeit in a restricted 
domain, the present data serve to re-open the question as to whether words are processed in parallel and, if so, the degree to which a model like E-Z Reader might be modified to accommodate to the fact. Schroyens, Vitu, Brysbaert and d'Ydewalle have (1999) recently suggested one possibility. This draws on the psychophysical work of Schiepers (1980), showing a strong curvilinear relationship between word identification time and eccentricity. Making inferences from decision time, and assuming visual processing across an array of words to occur in parallel, Schiepers estimated information to be delayed by about $100 \mathrm{~ms}$ for each degree of eccemtricity. One consequence of this fact is that performance in a task like reading, where words are spatially distributed around a given fixation point, will be conditioned by the operation of a restricted time window in which foveal and (delayed) parafoveal information can be optimally combined. For example, after a forward saccade, a fixation on a word will allow information about its word-ending, acquired on the current fixation, to be combined with information about its word-beginning, acquired on the previous fixation $^{\mathrm{xvi}}$. This is an attractive idea and would be compatible with some of the more paradoxical results in the present data, for example explaining why the system might require less time at the current location when the next location to be fixated is particularly informative or 'difficult'. The problem is that there is quite a lot of evidence against the operation of deadlines in word-to-word processing, and no evidence, as yet, in support of the proposed 'synchrony' mechanism.

Engbert and Kliegl (2001) have recently proposed an alternative, and computationally explicit, model of eye movement control in which lexical processing is also considered to be spatially distributed over an attentional window. Their model (Engbert, Longtin, \& Kliegl, 2001) is based on E-Z Reader model, but involves relaxing the crucial assumption that visual attention is switched from word to word with its operation restricted to a single word at a 
time. The model also replaces the relatively straightforward state-transition rules employed in the E-Z Reader model with more complex (and less psychologically plausible) semi-Markov processes (in which the probability of a transition is related to time spent in a given state). It would be premature to try evaluate this approach here, but it does illustrate that plausible extensions to current processing models to take account of parallel sources of information are feasible and may, indeed, represent the next step towards a more complete theory of eye movement control. 


\section{References}

Beauvillain, C. \& Beauvillain, P. (1995). Calibration of an eye movement system for use in reading. Behavior Research Methods, Instruments and Computers. 55, 1- 17.

Broadbent, D. E, \& Gregory, M. (1968). Visual perception of words differing in letter bigram frequency. Journal of Verbal Learning and Verbal Behavior, 7, 569 - 571.

Brysbaert, M. \& Vitu, F. (1998). Word-skipping: Implications for theories of eye movement control in reading. In G. Underwood (Ed.). Eye guidance in reading and scene perception ( pp. 135-147). Oxford: Elsevier.

Carpenter, P.A. \& Just, M. A. (1983). What your eyes do while your mind is reading. In K. Rayner (Ed.), Eye Movements in Reading: Perceptual and Language Processes (pp. 275305). New York: Academic Press.

Content, A. \& Radeau, M. ( 1988). Données statistiques sur la structure orthographique du francais. Cahiers de Psychologie Cognitive, 8, 399 - 404.

Content, A., Mousty, P. \& Radeau, M. (1990). Brulex: une base de données lexicales informatisée pour le francais écrit et parlé. L'Année Psychologique, 90, 551 - 566.

Deubel, H., O'Regan, J. K. \& Radach, R. (2000). Attention, information processing and eye movement control. In A. Kennedy, R. Radach, D. Heller and J. Pynte (Eds.) Reading as a Perceptual Process ( pp. 355 - 374). Oxford: Elsevier.

Doré, K. \& Beauvillain, C. (1997). Latency dependence of word-initial letter integration by the saccadic system. Perception \& Psychophysics, 59, 523 - 533.

Engbert, R., Longtin, A. \& Kliegl, R. (2001). A dynamical model of saccade generation in reading based on spatially distributed lexical processing. MS under review.

Engbert, R. \& Kliegl, R. (2001). Mathematical models of eye movements in reading: A possible role for autonomous saccades. Biological Cybernetics. In press. 
Findlay, J. M. \& Walker, R. (1999). A model of saccade generation based on parallel processing and competitive inhibition. Behavioral and Brain Sciences, 22, 661 - 721.

Grainger, J. (2000). From print to meaning via words? In A. Kennedy, R. Radach, D. Heller and J. Pynte (Eds.) Reading as a Perceptual Process ( pp. 147 - 161). Oxford: Elsevier.

Henderson, J. M. (1992).Visual attention and eye movement control during reading and picture viewing. In K. Rayner (Ed.). Eye Movements and Visual Cognition: Scene Perception and Reading ( pp. 260 - 283). New York: Springer-Verlag .

Henderson, J. M. \& Ferreira, F. (1990). Effects of foveal processing difficulty on the perceptual span in reading: Implications for attention and eye movement control. Journal of Experimental Psychology: Learning, Memory and Cognition, 16, 417 - 429.

Henderson, J. M. \& Ferreira, F. (1993). Eye movement control during reading: Fixation measures foveal but not parafoveal processing difficulty. Canadian Journal of Experimental Psychology, 47, 201 - 221.

Hoffman, J. E. (1998). Visual attention and eye movements. In H. Pashler (Ed.). Attention ( pp. 119 - 150). Hove: Psychology Press.

Hyönä, J. \& Pollatsek, A. (1998). Reading Finnish compound words: Eye fixations are affected by component morphemes. Journal of Experimental Psychology: Human Perception and Performance, 24, 1612-1627.

Hyönä, J. (1995). Do irregular letter combinations attract readers' attention? Evidence from fixation locations in words. Journal of Experimental Psychology: Human Perception and Performance, 21, 68 - 81 .

Hyönä, J. \& Pollatsek, A. (2000). Processing of Finnish Compound Words in Reading. In A. Kennedy, R. Radach, D. Heller and J. Pynte (Eds.) Reading as a Perceptual Process ( pp. 65 - 87). Oxford: Elsevier. 
Inhoff, A. W. \& Radach, R. (1998). Definition and computation of oculomotor measures in the study of cognitive processes. In G. Underwood (Ed.). Eye guidance in reading and scene perception ( pp. 29 - 53). Oxford: Elsevier.

Inhoff, A. W., Radach, R. Starr, M. \& Greenberg, S. (2000). Allocation of Visuo-Spatial Attention and Saccade Programming during Reading. In A. Kennedy, R. Radach, D. Heller and J. Pynte (Eds.) Reading as a Perceptual Process. Oxford: Elsevier. In Press.

Kennedy, A. (1998). The influence of parafoveal words on foveal inspection time: evidence for a processing trade-off. In G. Underwood (Ed.). Eye guidance in reading and scene perception ( pp. 149 - 223). Oxford: Elsevier.

Kennedy, A. (2000a). Parafoveal processing in word recognition. Quarterly Journal of Experimental Psychology, 53A, 429 - 455.

Kennedy, A (2000b). Attention allocation in reading. In A. Kennedy, R. Radach, D. Heller and J. Pynte (Eds.) Reading as a Perceptual Process ( pp. 193 - 220). Oxford: Elsevier.

Kennison, S. M. \& Clifton, C. (1995). Determinants of parafoveal preview benefit in high and low working memory capacity readers: Implications for eye movement control. Journal of Experimental Psychology: Learning, Memory and Cognition, 21, 68 - 81.

Kleigl, R., Olson, R. K. \& Davidson, B. J. (1982). Regression analyses as a tool for studying reading processes: Comment on Just and Carpenter's eye fixation theory. Memory and Cognition, 10, $287-296$.

McConkie, G. W. \& Rayner, K. (1975). The span of the effective stimulus during a fixation in reading. Perception \& Psychophysics, 17, 578 - 586.

Morrison, R. E. (1984). Manipulation of stimulus onset delay in reading: Evidence for parallel programming of saccades. Journal of Experimental Psychology: Human Perception and Performance, 10, 667 - 682. 
Morrison, R. E. \& Rayner, K. (1981). Saccade size in reading depends upon character spaces and not visual angle. Perception \& Psychophysics, 30, 395 - 396.

Murray, W. S. (1998). Parafoveal pragmatics. In G. Underwood (Ed.). Eye guidance in reading and scene perception ( pp. 181 - 199). Oxford: Elsevier.

O'Regan, J. K. (1989). Visual acuity, lexical structure and eye movements in word recognition. In B. Elsendoorn \& H. Bouma (Eds.). Working models of human perception ( pp. 261 - 292). London, Academic Press

O’Regan, J. K. (1990). Eye movements and reading. In E. Kowler (Ed.). Eye Movements and their role in Visual and Cognitive Processes ( pp. 395-453). Amsterdam: Elsevier.

Owswitz, S. E. (1963). The effects of word familiarity and letter structure familiarity on the perception of words. Technical Report No P-2820, Rand Corporation. Santa Monica: Rand Corporation Publications.

Pollatsek, A. \& Rayner, K. (1990). Eye movements and lexical access in reading. D. A. Balota, G. B. Flores d'Arcais \& K. Rayner (Eds.). Comprehension Processes in Reading ( pp. 143 - 163). Hillsdale: Erlbaum.

Pollatsek, A., Rayner, K. \& Balota, D. A. (1986). Inferences about eye movement control from the perceptual span in reading. Perception \& Psychophysics, 40, 123 - 130.

Pollatsek, A., Raney, G. E., LaGasse, L. \& Rayner, K. (1993). The use of information below fixation in reading and in visual search. Canadian Journal of Experimental Psychology, $47,179-200$.

Prinz, W. (1984). Attention and sensitivity in visual search, Psychological Research, 45, 355 $-366$.

Pynte, J. \& Masselot, M-F. (1980). Peut-on obtenir des effets de lateralitie dans le champ bihemispherique? Cahiers de Psychologie, 23, 163 - 178. 
Pynte, J., Kennedy, A. \& Murray, W. S. (1991). Within-word inspection strategies in continuous reading: Time course of perceptual, lexical and contextual processes. Journal of Experimental Psychology: Human Perception and Performance, 17, 458 470.

Radach, R. \& Kempe, V. (1993). An individual analysis of initial fixation positions in reading. In G. d'Ydewalle \& J. Van Rensbergen (Eds.). Perception and Cognition: Advances in Eye Movement Research ( pp. 213 - 225). Amsterdam: Elsevier.

Radach, R. \& Heller, D. (2000). Relations between spatial and temporal aspects of eye movement control. In A. Kennedy, R. Radach, D. Heller and J. Pynte (Eds.) Reading as a Perceptual Process ( pp. 165 - 191). Oxford: Elsevier.

Reichle, E. D., Pollatsek, A., Fisher, D. L. \& Rayner, K. (1998). Towards a model of eye movement control in reading. Psychological Review, 105, 125-157.

Rayner, K. (1975). The perceptual span and peripheral cues in reading. Cognitive Psychology, 7, $65-81$.

Rayner, K. (1995). Eye movements and cognitive processes in reading, visual search, and scene perception. In J. M. Findlay, R. Walker \& R. W. Kentridge. (Eds.). Eye Movement Research: Mechanisms, Processes and Applications ( pp. 3 - 21). Amsterdam: NorthHolland.

Rayner, K. (1977). Visual attention in reading: Eye movements reflect cognitive processes. Memory \& Cognition, 4, 443 - 448.

Rayner, K. (1998). Eye movements in reading and information processing: 20 years of research. Psychological Bulletin, 124, 372-422. 
Rayner, K. \& Duffy, S. A. (1986). Lexical complexity and fixation times in reading: Effects of word frequency, verb complexity, and lexical ambiguity. Memory and Cognition, 14, $191-201$.

Rayner, K. \& Fischer, M. F. (1996). Mindless reading revisited: Eye movements during reading and scanning are different. Perception \& Psychophysics, 58, 734 - 747.

Rayne, K. \& McConkie, G. W. (1976). What guides a reader's eye movements? Vision Research, 16, 829 - 837.

Rayner, K., Fischer, M. F. \& Pollatsek, A. (1998). Unspaced text interferes with both word identification and eye movement control, Vision Research, 38, 1129 - 1144.

Rayner, K. \& Morris, R. (1992). Eye movement control in reading: Evidence against semantic pre-processing. Journal of Experimental Psychology: Human Perception and Performance, $18,163-172$.

Rayner, K. \& Pollatsek, A. (1989). The Psychology of Reading. Englewood Cliffs, N. J:

Prentice-Hall.

Rayner, K. \& Raney, G. E. (1996). Eye movement control in reading and visual search: Effects of word frequency. Psychonomic Bulletin \& Review, 3, 238 - 244.

Rayner, K., Sereno S. C. \& Raney G. E. (1996). Eye movement control in reading: A comparison of two types of models. Journal of Experimental Psychology: Human Perception and Performance, 22, 1-13.

Rice, G. A. \& Robinson, D. O. (1975). The role of bigram frequency in the perception of words and non-words. Memory and Cognition, 3, 513 - 518.

Shallice, T. (1964). The detection of change, and the perceptual moment hypothesis. British Journal of Statistical Psychology, 17, 113 - 135. 
Schiepers, C. (1980). Response latency and accuracy in visual word recognition. Perception \& Psychophysics, 27, 71-81.

Schroyens, W., Vitu, F., Brysbaert, M. \& d'Ydewalle, G. (1999). Visual attention and eyemovement control during reading: The case of parafoveal processing. Quarterly Journal of Experimental Psychology, 52A, 1021 - 1046.

Slowiaczek, M. L. \& Rayner, K. (1987). Sequential masking during eye fixations in reading. Bulletin of the Psychonomic Society, 25, 175 - 178.

Underwood, G., Binns, A. \& Walker, S. (2000). Attentional demands on the processing of neighbouring words. In A. Kennedy, R. Radach, D. Heller and J. Pynte (Eds.) Reading as a Perceptual Process ( pp. 247 - 268). Oxford: Elsevier.

Underwood, G., Clews, S. \& Everatt, J. (1990). How do readers know where to look next? Local information distributions influence eye fixations. Quarterly Journal of Experimental Psychology, 42A, 39-65.

Vonk, W., Radach, R. \& van Rijn, H. (2000). Eye guidance and the saliency of word beginnings in reading text. In A. Kennedy, R. Radach, D. Heller and J. Pynte (Eds.) Reading as a Perceptual Process ( pp. 269 - 299). Oxford: Elsevier. 


\begin{tabular}{|l|l|l|l|l|l|l|l|}
\hline Word 1 & \multicolumn{1}{|c|}{ Word 2 } & \multicolumn{1}{|c|}{$\begin{array}{c}\text { Word 1 } \\
\text { Properties }\end{array}$} & $\begin{array}{c}\text { Word 2 } \\
\text { Properties }\end{array}$ & Word 1 & Word 2 & $\begin{array}{c}\text { Word 1 } \\
\text { Properties }\end{array}$ & Properties \\
\hline installer & derme & Long HF & INF Short LF & apparence & marte & Long HF & UNINF Short LF \\
\hline granivore & nonce & Long LF & INF Short LF & colmatage & encan & Long LF & UNINF Short LF \\
\hline recul & nonne & Short HF & INF Short LF & mardi & coran & Short HF & UNINF Short LF \\
\hline carpe & motte & Short LF & INF Short LF & carme & cornu & Short LF & UNINF Short LF \\
\hline remercier & armurerie & Long HF & INF Long LF & attention & afficheur & Long HF & UNINF Long LF \\
\hline concessif & nomadisme & Long LF & INF Long LF & remontoir & empennage & Long LF & UNINF Long LF \\
\hline grain & mielleuse & Short HF & INF Long LF & place & graissage & Short HF & UNINF Long LF \\
\hline morue & actionner & Short LF & INF Long LF & manne & plantaire & Short LF & UNINF Long LF \\
\hline influence & genou & Long HF & INF Short HF & approuver & plaie & Long HF & UNINF Short HF \\
\hline encadreur & sorte & Long LF & INF Short HF & versifier & appui & Long LF & UNINF Short HF \\
\hline marge & votre & Short HF & INF Short HF & fouet & appel & Short HF & UNINF Short HF \\
\hline carat & femme & Short LF & INF Short HF & rouet & corps & Short LF & UNINF Short HF \\
\hline assemblée & hautement & Long HF & INF Long HF & industrie & accomplir & Long HF & UNINF Long HF \\
\hline remplumer & exigeante & Long LF & INF Long HF & fouettard & président & Long LF & UNINF Long HF \\
\hline verbe & justifier & Short HF & INF Long HF & carte & remarquer & Short HF & UNINF Long HF \\
\hline carie & semblable & Short LF & INF Long HF & verge & apprendre & Short LF & UNINF Long HF \\
\hline
\end{tabular}

Table 1. Examples of materials used in the experiment. 


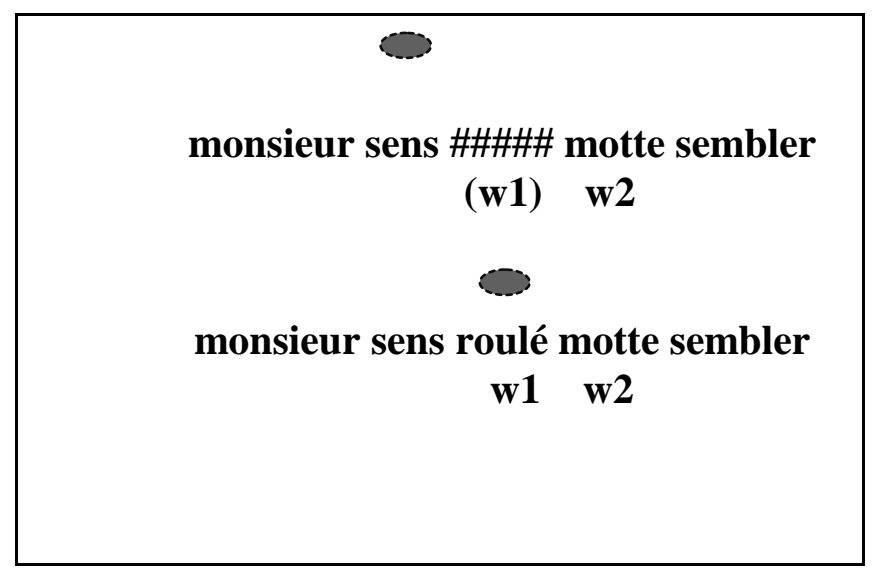

FIGURE 1: Illustration of experimental procedure. Experimental words were embedded in strings five words in length. While the eyes were to the left of an invisible boundary, defined by the space prior to Word 1, this word was masked. When the eyes shifted to the right of this boundary, the word was permanently unmasked. (Note, hashes are shown to illustrate masking: the experimental procedure used a pixel-randomisation procedure.) 


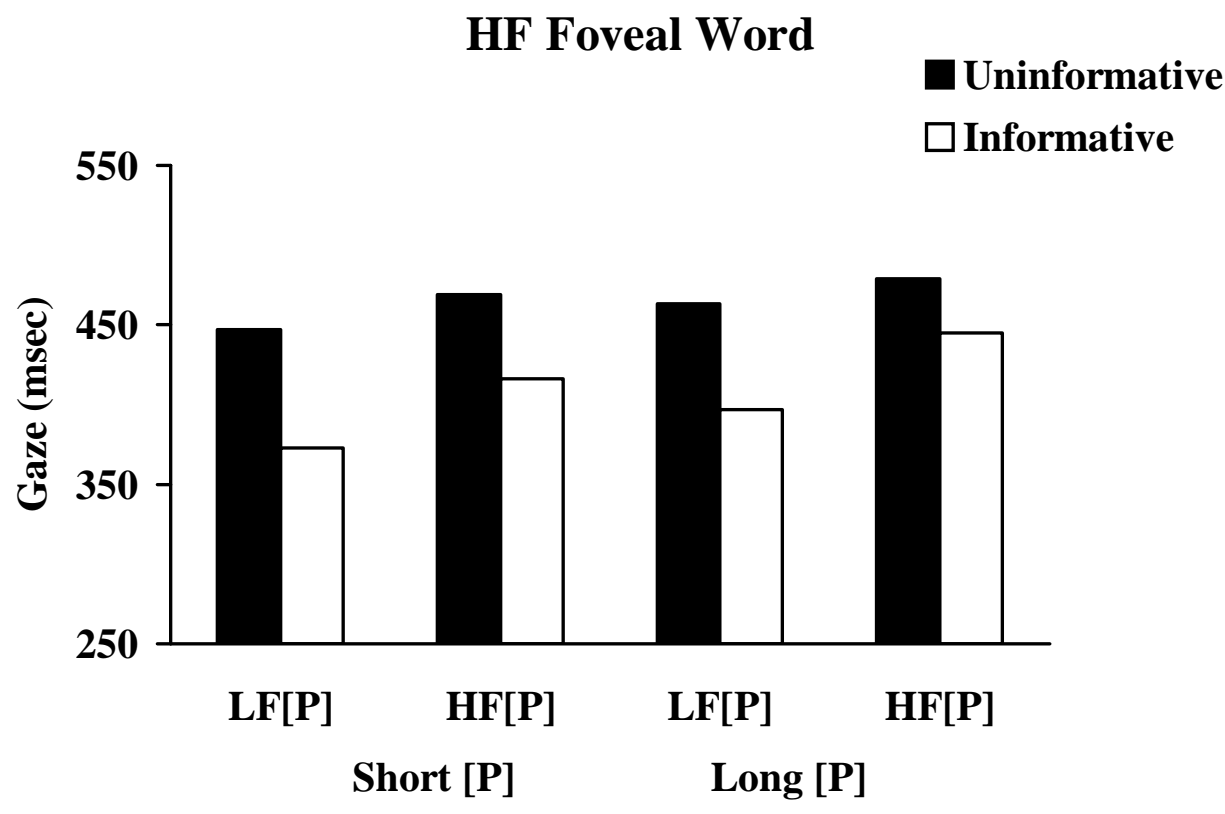

FIGURE 2. Mean gaze duration as a function of the length, frequency and informativeness of a parafoveal target word for a high frequency short foveal stimulus.

The data represent the quadrant of the design replicating the conditions obtaining in the original 'clothes search' study (see Figure 8, Kennedy, 2000). 


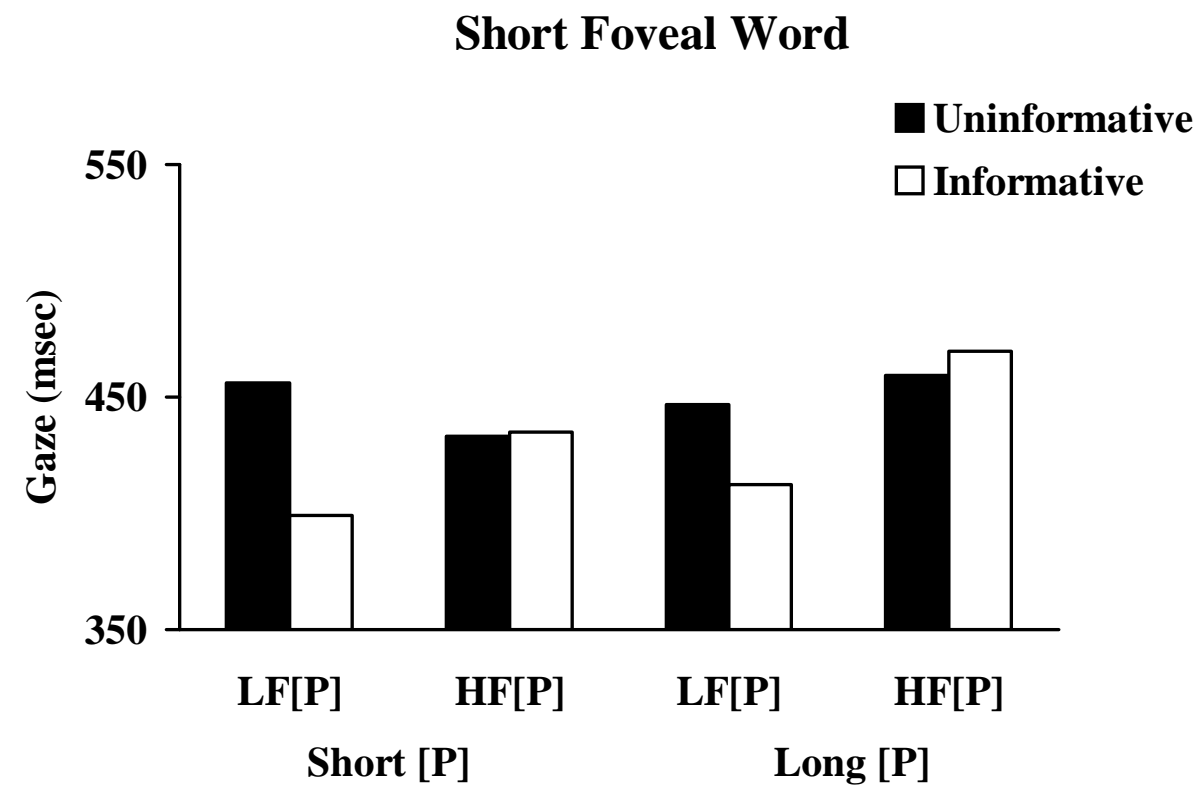

FIGURE 3. Mean gaze duration as a function of frequency, length and informativeness of a parafoveal target word for short foveal stimuli. 


\section{Short Foveal Word}

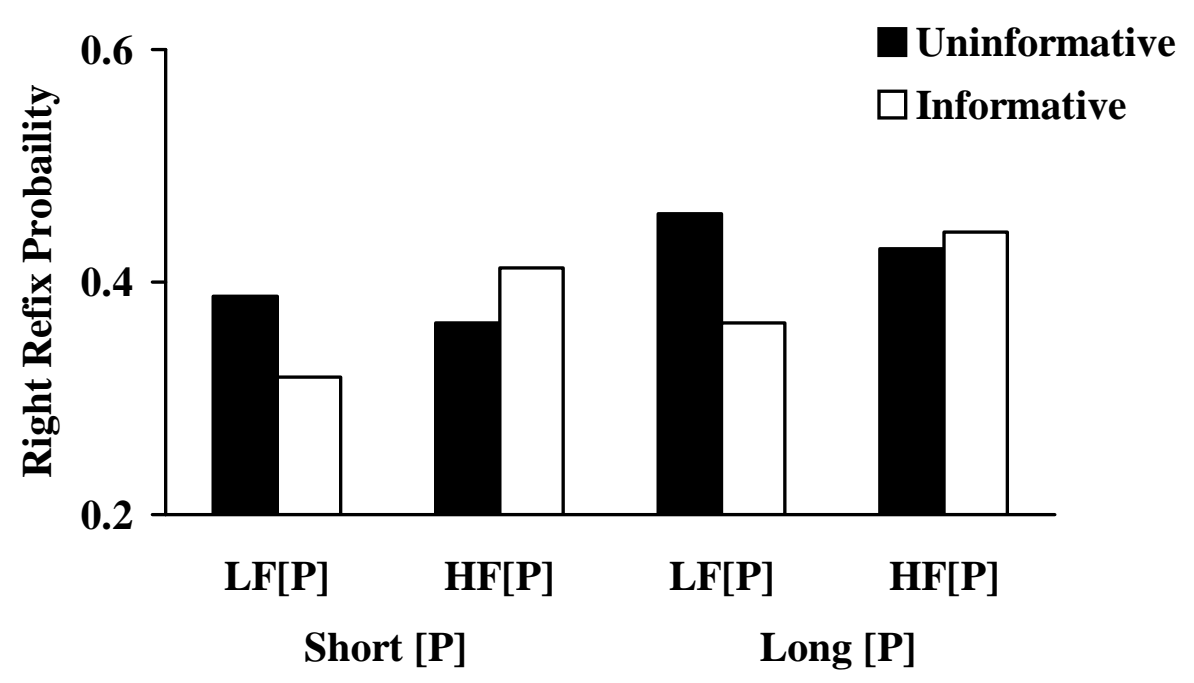

FIGURE 4. Right-going refixation probability as a function of frequency, length and informativeness of a parafoveal target word for short foveal stimuli. 


\section{Short Foveal Word}

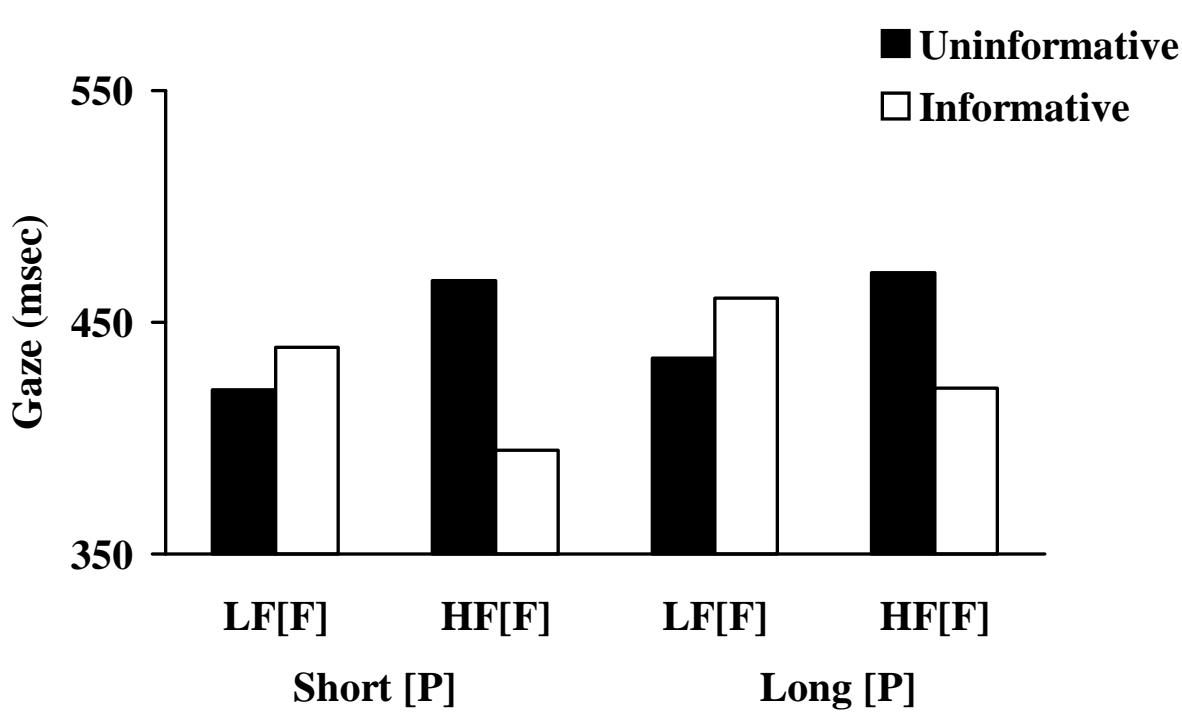

FIGURE 5. Mean gaze duration for short foveal stimuli as a function of a parafoveal target word informativeness and length and foveal word frequency. 


\section{Short Foveal Word}

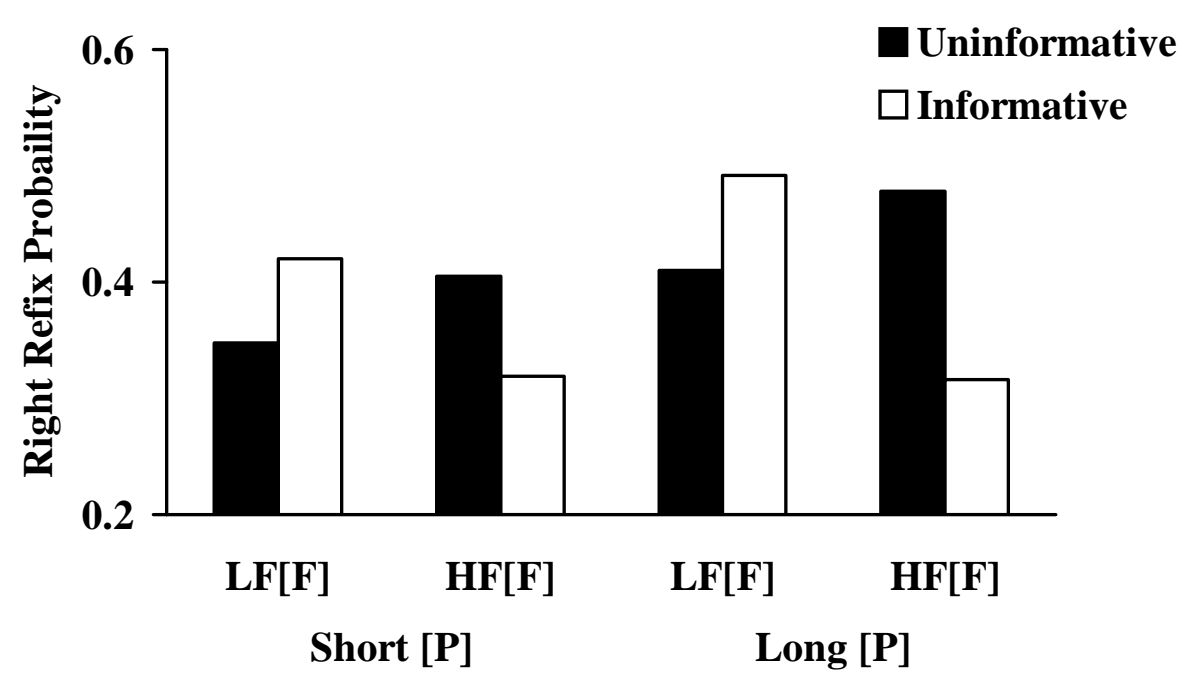

FIGURE 6. Right-going refixation probability for short foveal stimuli as a function of a parafoveal target word informativeness and length and foveal word frequency. 


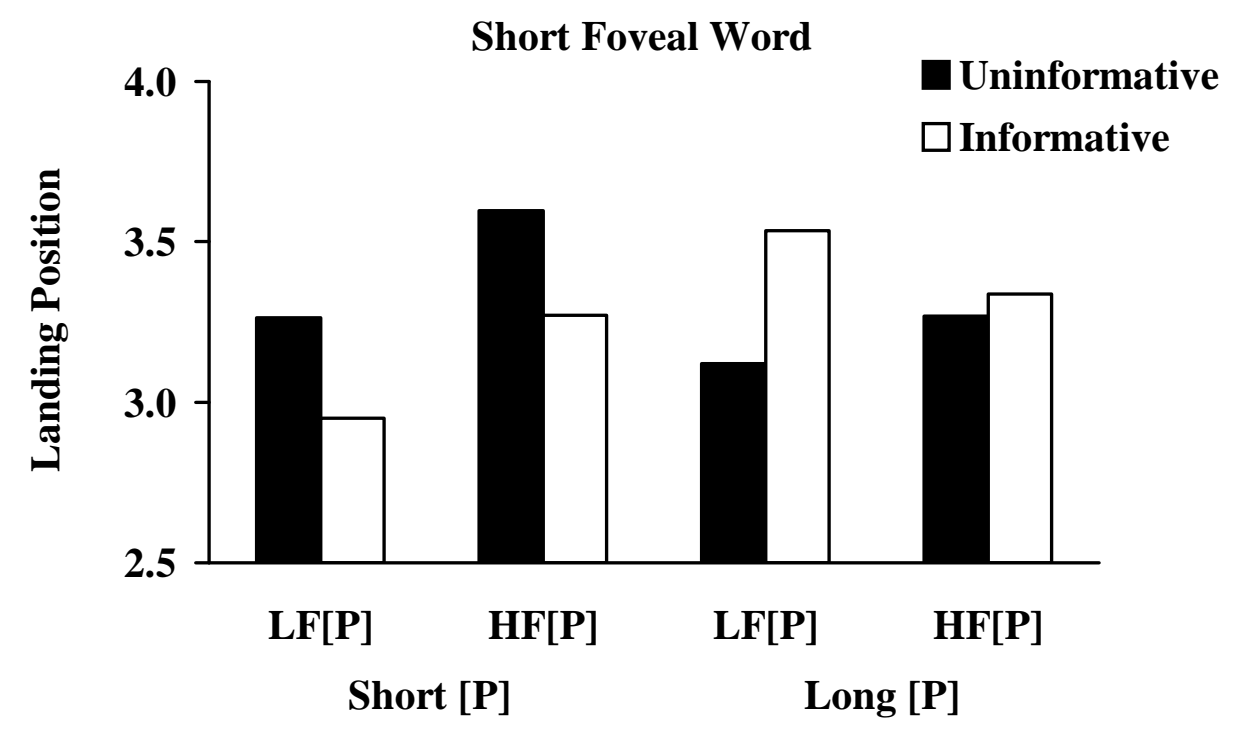

FIGURE 7: Mean landing position on parafoveal target word arriving from short foveal words, as a function of the frequency and informativeness of a parafoveal target word. 


\section{Long Foveal Word}

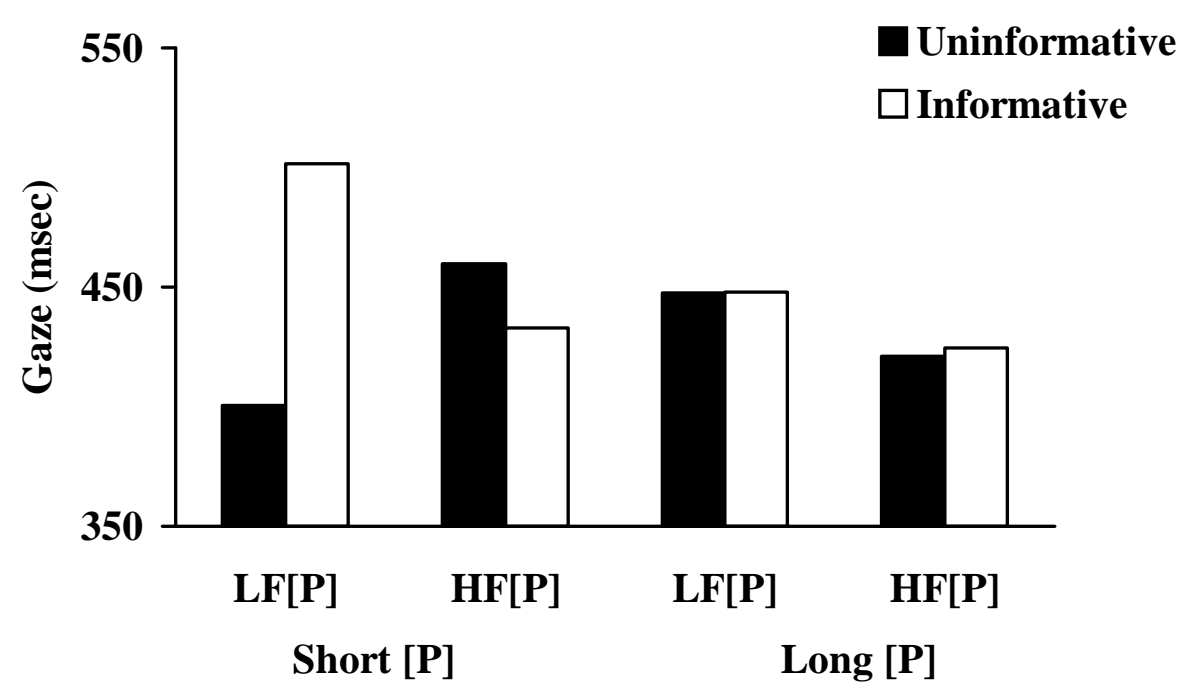

FIGURE 8: Mean gaze duration on long foveal stimuli as a function of length, frequency and informativeness of a parafoveal target word. 


\section{Long Foveal Word}

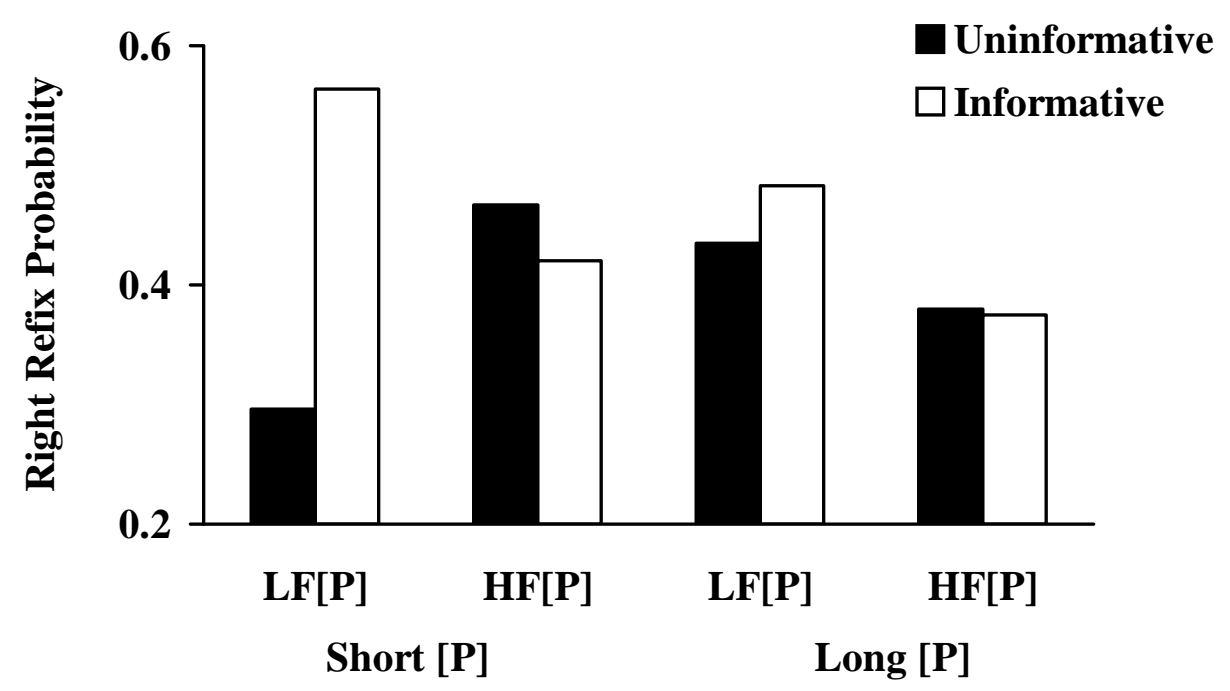

FIGURE 9: Right-going refixation probability for long foveal stimuli as a function of length, frequency and informativeness of a parafoveal target word (compare with Figure 8). 


\section{Long Foveal Word}

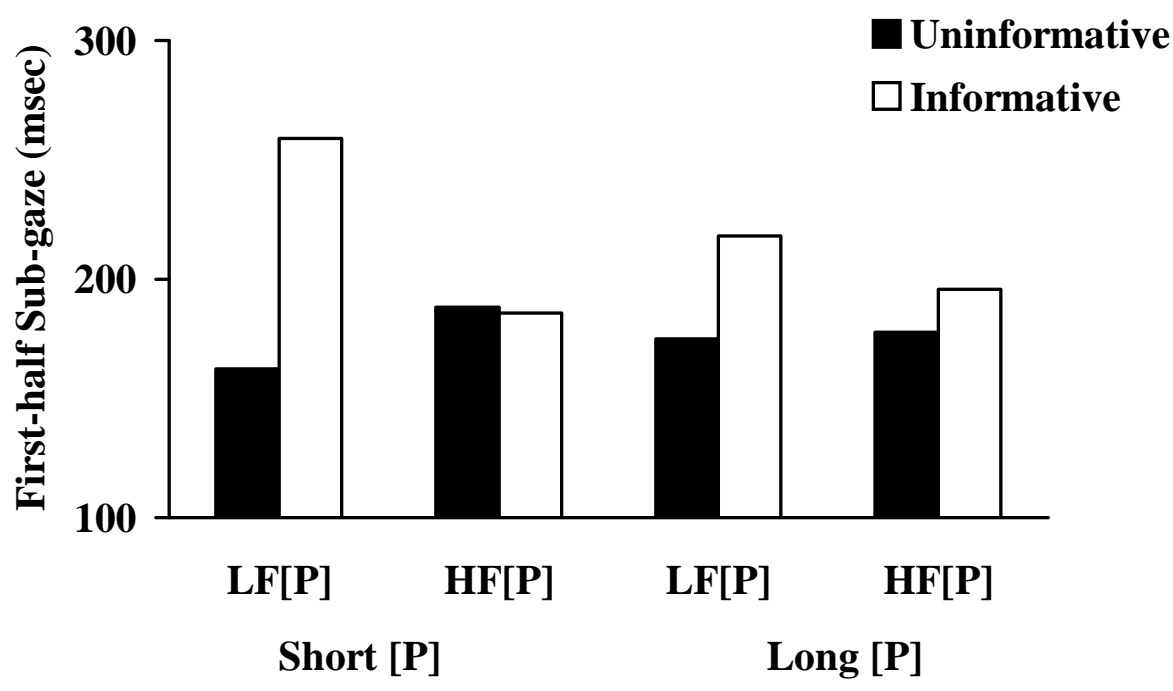

FIGURE 10: Mean sub-gaze duration (first half of long foveal stimuli) as a function of length, frequency and informativeness of a parafoveal target word. 


\section{Long Foveal Word}

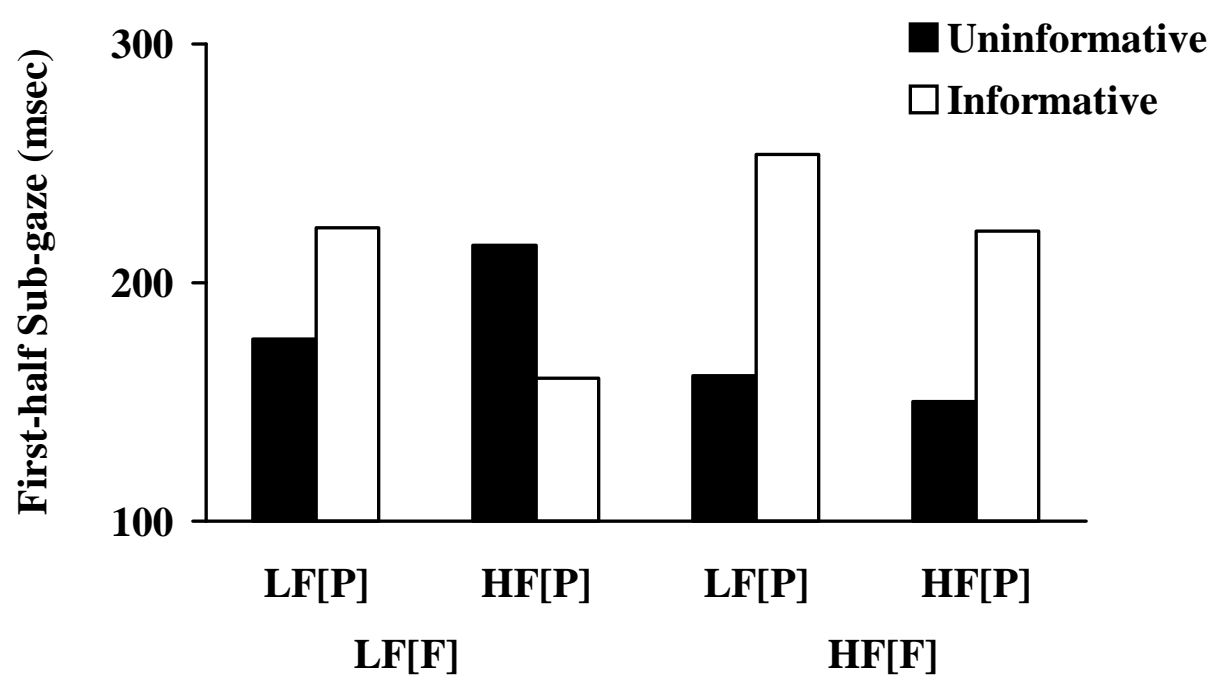

FIGURE 11: Mean sub-gaze duration (first half of long foveal stimuli) as a function of frequency and informativeness of the parafoveal target and frequency of the foveal word. 


\section{Long Foveal Word}

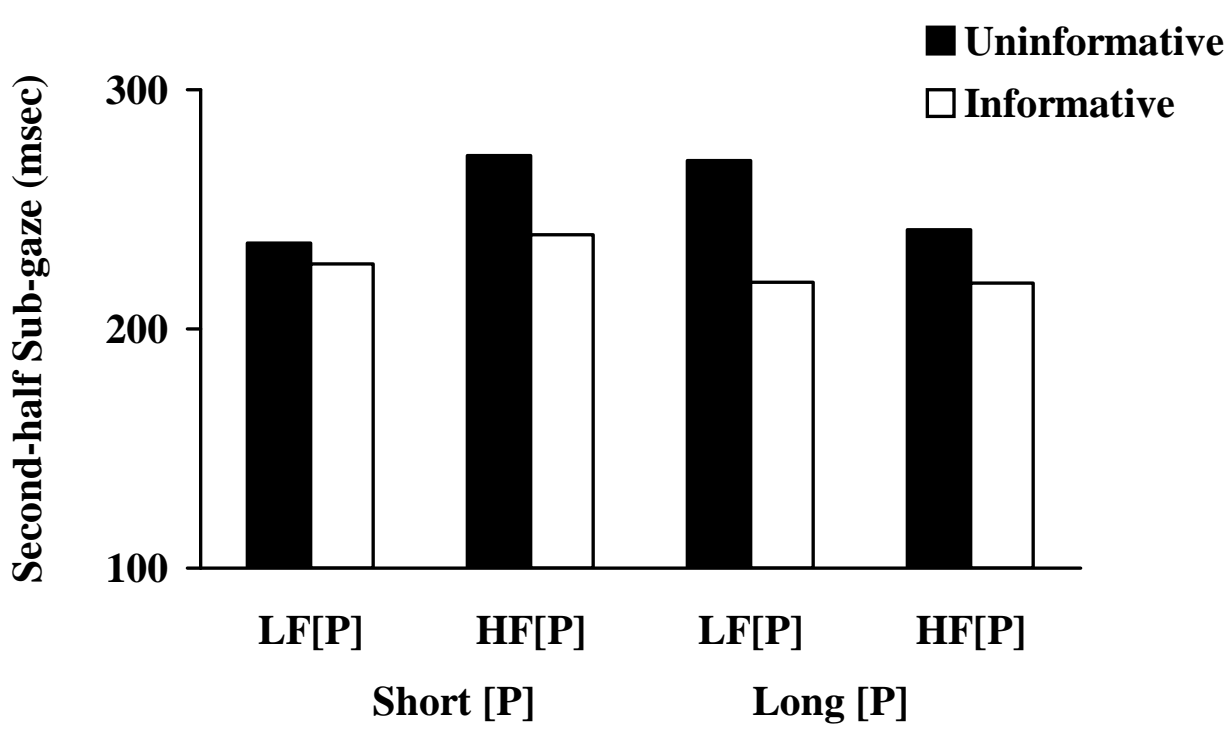

FIGURE 12: Mean sub-gaze duration (second half of long foveal stimuli) as a function of length, frequency and informativeness of a parafoveal target word. 


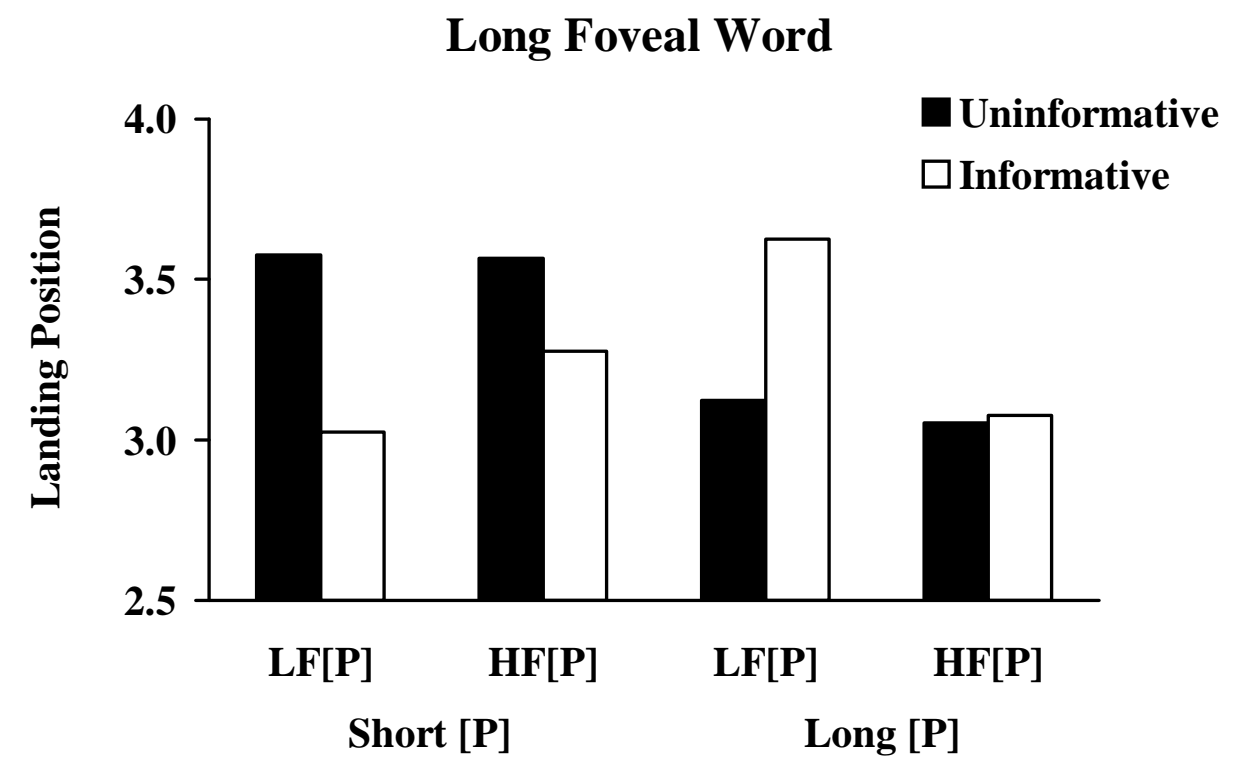

FIGURE 13: Mean landing position on the parafoveal word arriving from long foveal words, as a function of the frequency and informativeness of a parafoveal target. 
Short Foveal Word

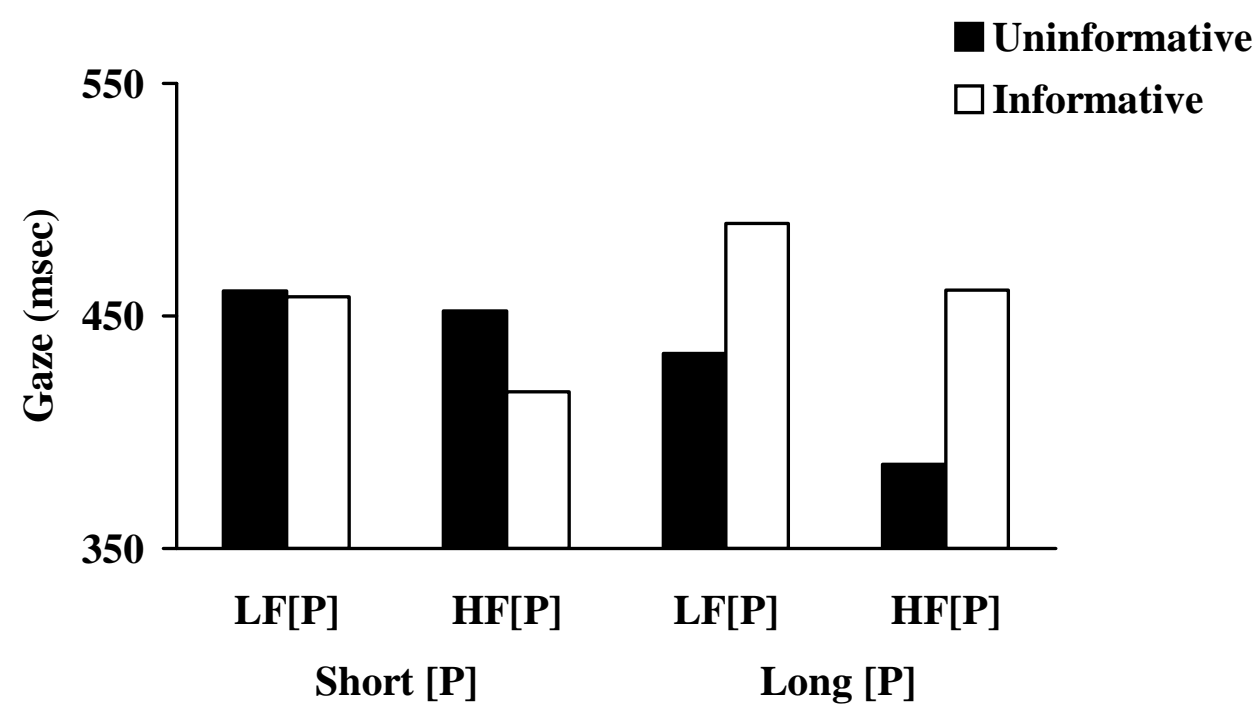

FIGURE 14: Mean gaze duration on the parafoveal target word following inspection of a short foveal stimulus as a function of length, frequency and informativeness of the target word (compare with Figure 3). 


\section{Long Foveal Word}

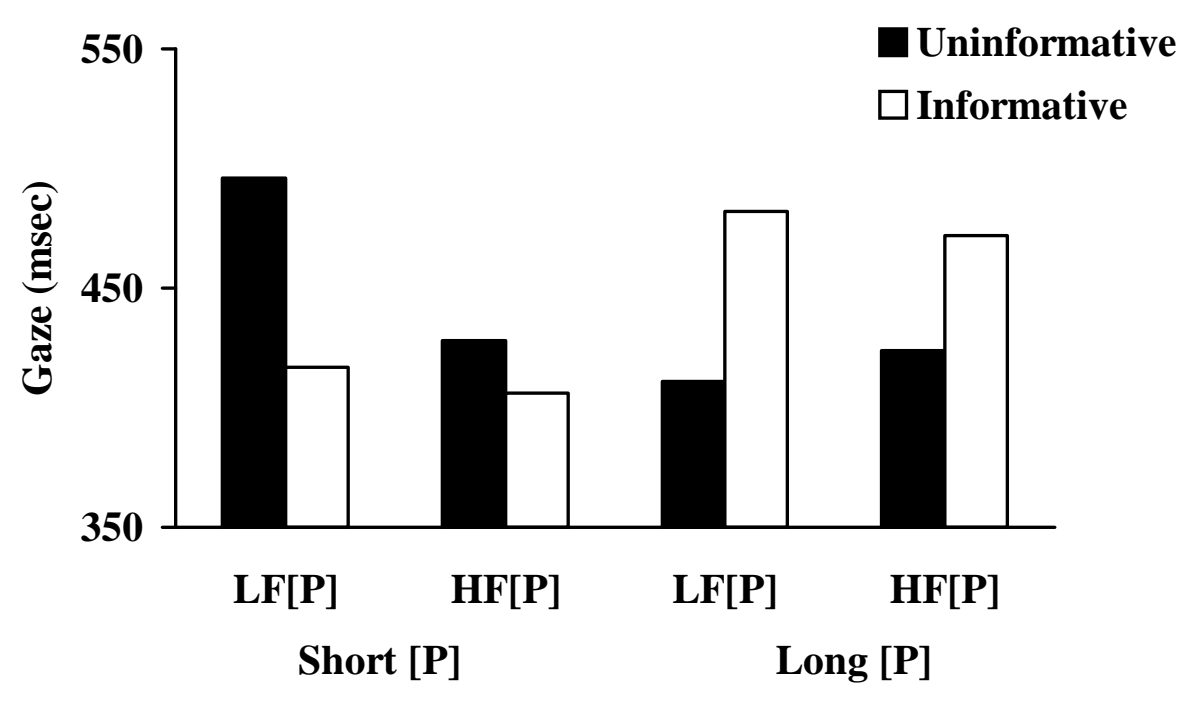

FIGURE 15: Mean gaze duration on the parafoveal word following inspection of a long foveal stimulus as a function of length, frequency and informativeness of the parafoveal word (compare with Figure 8). 


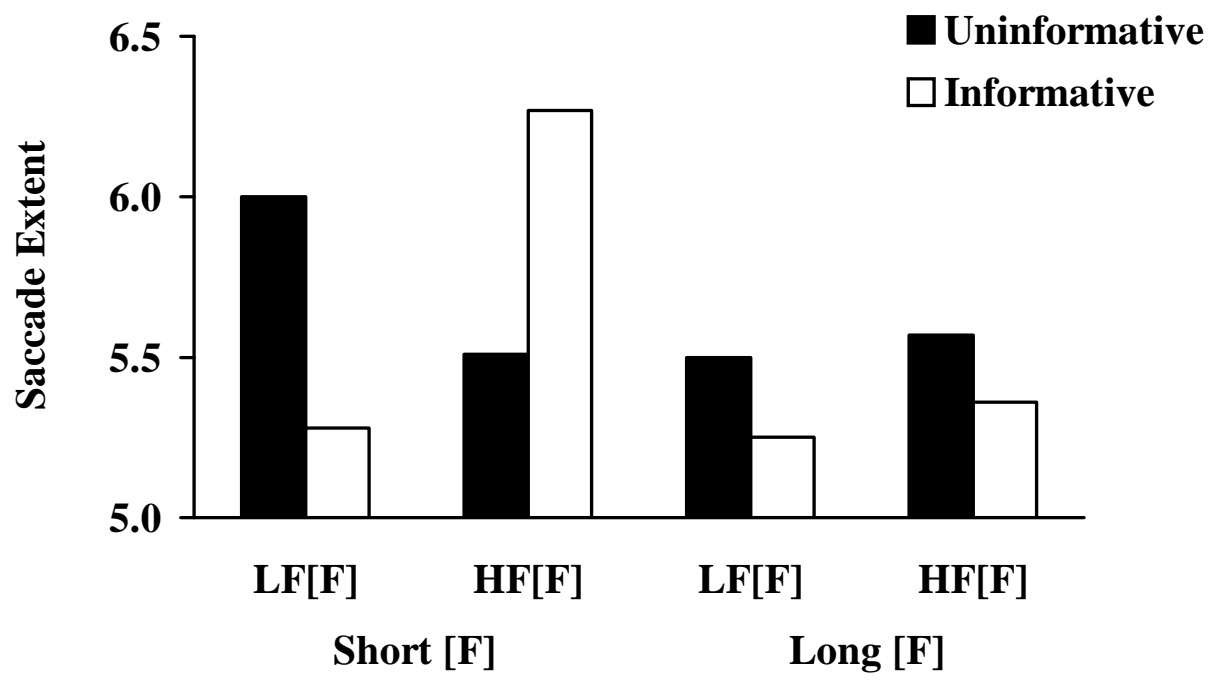

FIGURE 16: Initial saccade extent, regardless of landing position, as a function of the informativeness of the parafoveal target $[\mathrm{P}]$ and the length and frequency of the foveal launch site $[\mathrm{F}]$. 


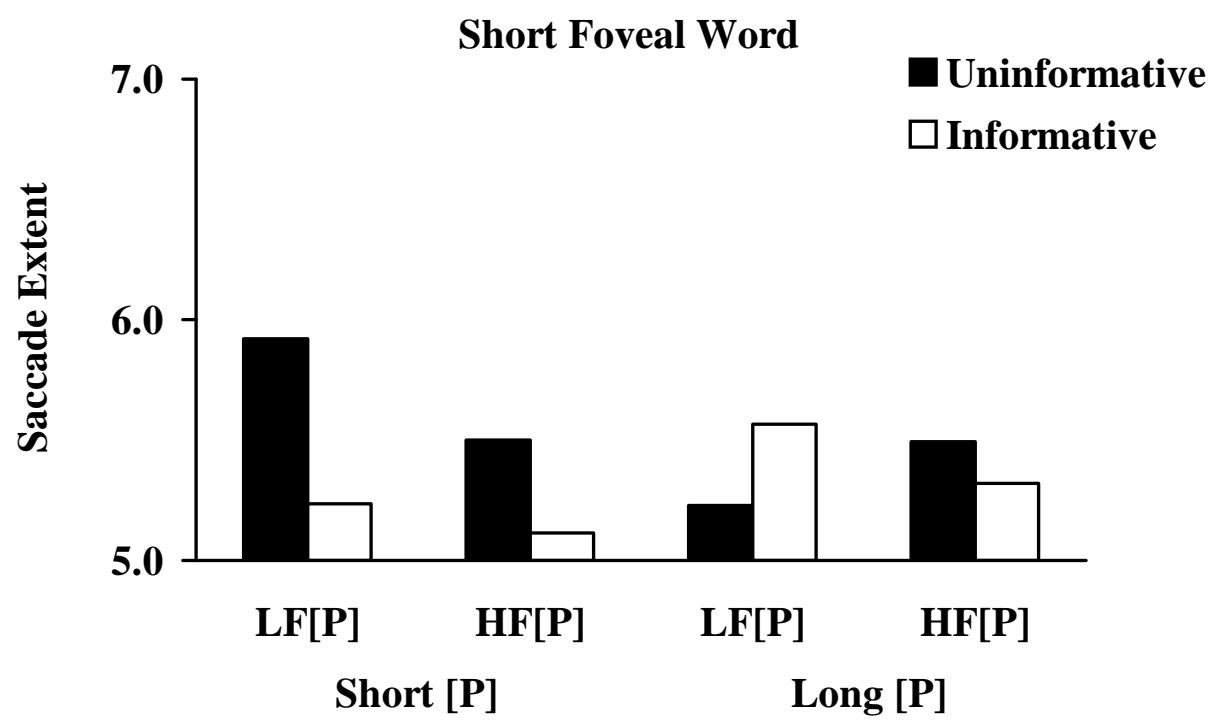

FIGURE 16a: Saccade Extent (to anywhere) on parafoveal target word arriving from short foveal words, as a function of the frequency and informativeness of a parafoveal target word. Interaction NS F1 $2.75 \mathrm{p}=0.10 \mathrm{~F} 2$ ? 


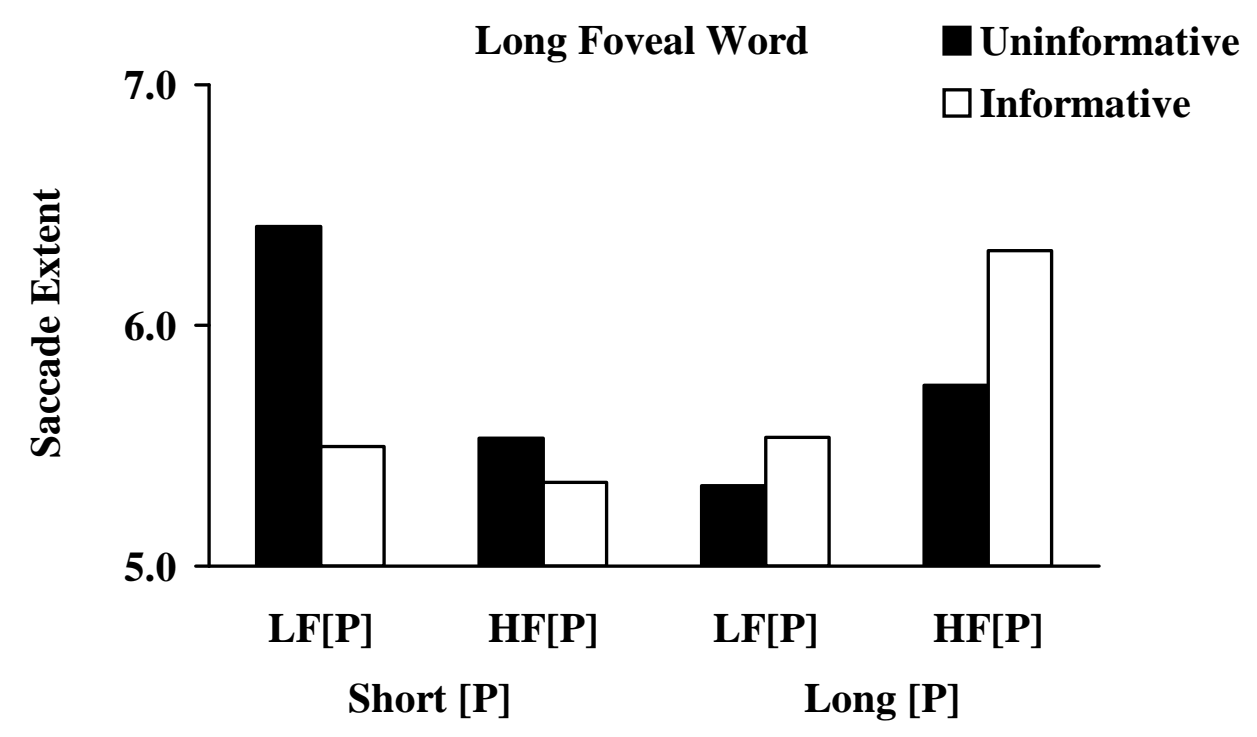

FIGURE 16b: Saccade Extent (to anywhere) on parafoveal target word arriving from long foveal words, as a function of the frequency and informativeness of a parafoveal target word. Interaction NS F1<1 F2=1.662 


\title{
Footnotes
}

\begin{abstract}
${ }^{\mathrm{i}}$ We are greatly indebted to Marc Brysbeart, Wayne Murray, Keith Rayner and an anonymous referee for many helpful comments on an earlier draft of this paper.

${ }^{\text {ii }}$ Pollatsek \& Rayner (1990) suggest that 'integrative processes' might modulate local processing difficulty, with competition between a decision to stay and a decision to execute the next saccade. This avoids postulating a deadline, but the proposal cannot account for the totality of data, some of which are derived from tasks which did not call for high-level integration.

iii Interestingly, although it is rarely made explicit, letter-level processing within a word is typically seen as going on in parallel (Slowiaczek \& Rayner, 1987), with processing between words seen as serial and sequential (Murray, 1998; Kennedy, 2000b).

${ }^{\text {iv }}$ Indeed, as Inhoff et al (2000) point out a significant advantage of this position is that it is consonant with the notion of saccades being directed towards the current focus of attention, rather than away from it, as demanded by the $E-Z$ Reader model.
\end{abstract}

${ }^{\mathrm{v}}$ This is, of course, the reason that saccade extent in text processing is reported in characters and not degrees of visual angle.

${ }^{\text {vi }}$ Radach \& Heller (2000) term this the 'negative pre-processing hypothesis'.

vii Interestingly, the notion that 're-fixate' might be a default condition on first fixating a word is a component of the serial E-Z Reader model. The proposal that the pre-lexical familiarity check acts to cancel this could be considered as a form of process-monitoring mechanism, although this is not the interpretation given by Reichle et al.

viii Masking is illustrated in the Figure by means of hashes. In the actual experiment, a process of pixel randomisation was employed (see text for details).

${ }^{\text {ix }}$ Referees have pointed out that the short high frequency parafoveal words appeared to be more frequent than long high frequency parafoveal words. Imbalances of this kind are an almost inevitable result of attempts to achieve orthogonal manipulation of length, frequency and informativeness. It should be noted, however, that in all cases the set of low frequency words were of considerably lower frequency.

${ }^{\mathrm{x}}$ Concerns over a possible lack of power in a design with cell means based on three observations per subject can be met by noting that within the split-plot design as a whole each condition main effect is based on 48 observations (32 df).

${ }^{\mathrm{xi}}$ The outcome appears to conflict with that of Underwood \& Binns (2000) but that study did not manipulate frequency and initial letter constraint orthogonally.

xii The overall skip rate for experimental words was 1.8\%. Skip rate for the short pre-foveal word was $2.3 \%$ (trials involving skips were excluded from the analysis). A referee has correctly pointed out that in this respect our task tapped strategies which may have been atypical of normal reading; although the low skip rate does allow the analyses to avoid some of the problems caused by distortions to launch and landing position caused by skipping

xiii This was confirmed by separate analyses of foveal word launch position for this data set. Contrary to the predictions derived from the Processing Difficulty Hypothesis, there were no systematic effects on saccade extent from the foveal to the parafoveal word.

${ }^{\text {xiv }}$ In fact, Pynte, Kennedy \& Murray (1991) demonstrate that refixation probability for a long word initially fixated to its extreme right is close to 1.0 (see also Hyönä, 1995).

${ }^{\mathrm{xv}}$ Zero fixation on a component half was treated as a point on the scale, thus allowing sub-gaze on the two 
halves of the word to sum to total gaze.

${ }^{\mathrm{xvi}}$ We are grateful to Marc Brysbaert for this example. 